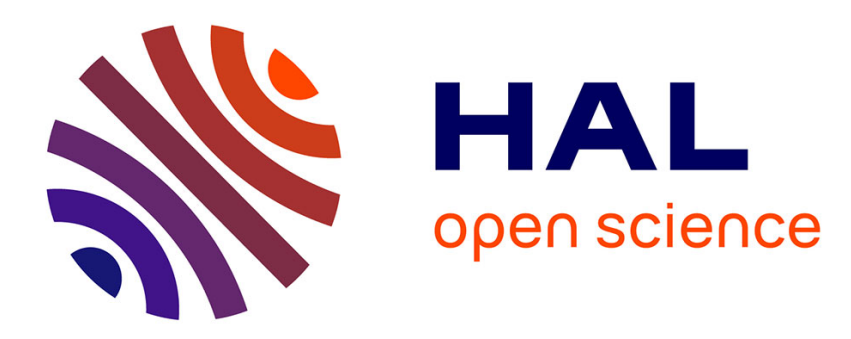

\title{
A non-local theory applied to high cycle multiaxial fatigue
}

Franck Morel, Thierry Palin-Luc

\section{To cite this version:}

Franck Morel, Thierry Palin-Luc. A non-local theory applied to high cycle multiaxial fatigue. Fatigue and Fracture of Engineering Materials and Structures, 2002, 25 (7), pp.649-665. 10.1046/j.14602695.2002.00527.x . hal-01376167

\section{HAL Id: hal-01376167 https://hal.science/hal-01376167}

Submitted on 4 Oct 2016

HAL is a multi-disciplinary open access archive for the deposit and dissemination of scientific research documents, whether they are published or not. The documents may come from teaching and research institutions in France or abroad, or from public or private research centers.
L'archive ouverte pluridisciplinaire HAL, est destinée au dépôt et à la diffusion de documents scientifiques de niveau recherche, publiés ou non, émanant des établissements d'enseignement et de recherche français ou étrangers, des laboratoires publics ou privés. 


\title{
A non-local theory applied to high cycle multiaxial fatigue
}

\author{
F. MOREL ${ }^{1}$ and T. PALIN-LUC ${ }^{2}$ \\ ${ }^{1}$ E.N.S.M.A., Laboratoire de Mécanique et de Physique des Matériaux (LMPM), UMR 6617, Site du Futuroscope, BP 109, 86960 Futuroscope Cedex, France \\ ${ }^{2}$ E.N.S.A.M., CER de Bordeaux, Laboratoire Matériaux Endommagement Fiabilitéet Ingénierie des Procédés, (LAMEFIP), EA 2727, Esplanade des Arts et \\ Métiers, 33405 Talence Cedex, France
}

A B S TRACT The stress gradient effect on the fatigue limit is an important factor which has to be taken into account for an efficient transfer of fatigue data from laboratory tests to design of industrial components. A short review of some multiaxial high cycle fatigue criteria considering this effect is presented. On the basis of the two local mesoscopic approaches of Papadopoulos, two new non-local high cycle multiaxial fatigue criteria are developed. These proposals are based on the concept of volume influencing fatigue crack initiation. Their predictions are compared with experimental multiaxial fatigue data on four materials (a mild steel, two high strength steels and a spheroidal graphite cast iron). The accuracy of the two local Papadopoulos criteria and of the non-local proposals are compared and discussed, together with the physical interpretation of the threshold defining the volume influencing fatigue crack initiation.

Keywords criterion; critical plane; gradient effect; high cycle fatigue; multiaxial loading path; non-local criterion.

NOMENCLATURE

$$
\begin{aligned}
a, b & =\text { material parameters of the Dang Van criterion } \\
\vec{n} & =\text { unit vector normal to a material plane } \\
f_{R-1} & =\text { fully reversed four point rotating bending endurance limit } \\
p_{t}, q_{t}, p_{m}, q_{m} & =\text { material parameters } \\
s_{-1} & =\text { fully reversed tension endurance limit } \\
t_{-1} & =\text { fully reversed torsion endurance limit } \\
A \% & =\text { elongation at failure } \\
C_{\mathrm{i}} & =\text { critical point } \\
E & =\text { Young modulus } \\
E_{\mathrm{sec}} & =\text { secant modulus } \\
M & =\text { considered point in the material } \\
H_{t}, H_{m}, H & =\text { heterogeneity factors } \\
M_{\sigma} & =\text { root mean square value of } T_{\sigma} \\
N & =\text { normal stress to the material plane defined by } \vec{n} \\
\mathrm{REP} & =\text { relative error of prediction } \\
R & =\text { stress ratio } \sigma_{\text {min }} / \sigma_{\text {max }} \\
R_{0.2} & =\text { yield stress with a plastic strain of } 0.2 \% \\
R m & =\text { maximum stress in monotonic tension } \\
R u & =\text { ultimate stress in monotonic tension } \\
T & =\text { period of a cyclic load } \\
T_{a} & =\text { resolved shear stress amplitude } \\
T_{\sigma} & =\text { root mean square value of } T_{a} \\
T_{\Sigma} & =\text { max } \theta, \phi \\
V^{*} & =\text { volume influencing fatigue crack initiation } \\
V_{90 \%} & =\text { highly stressed volume }
\end{aligned}
$$




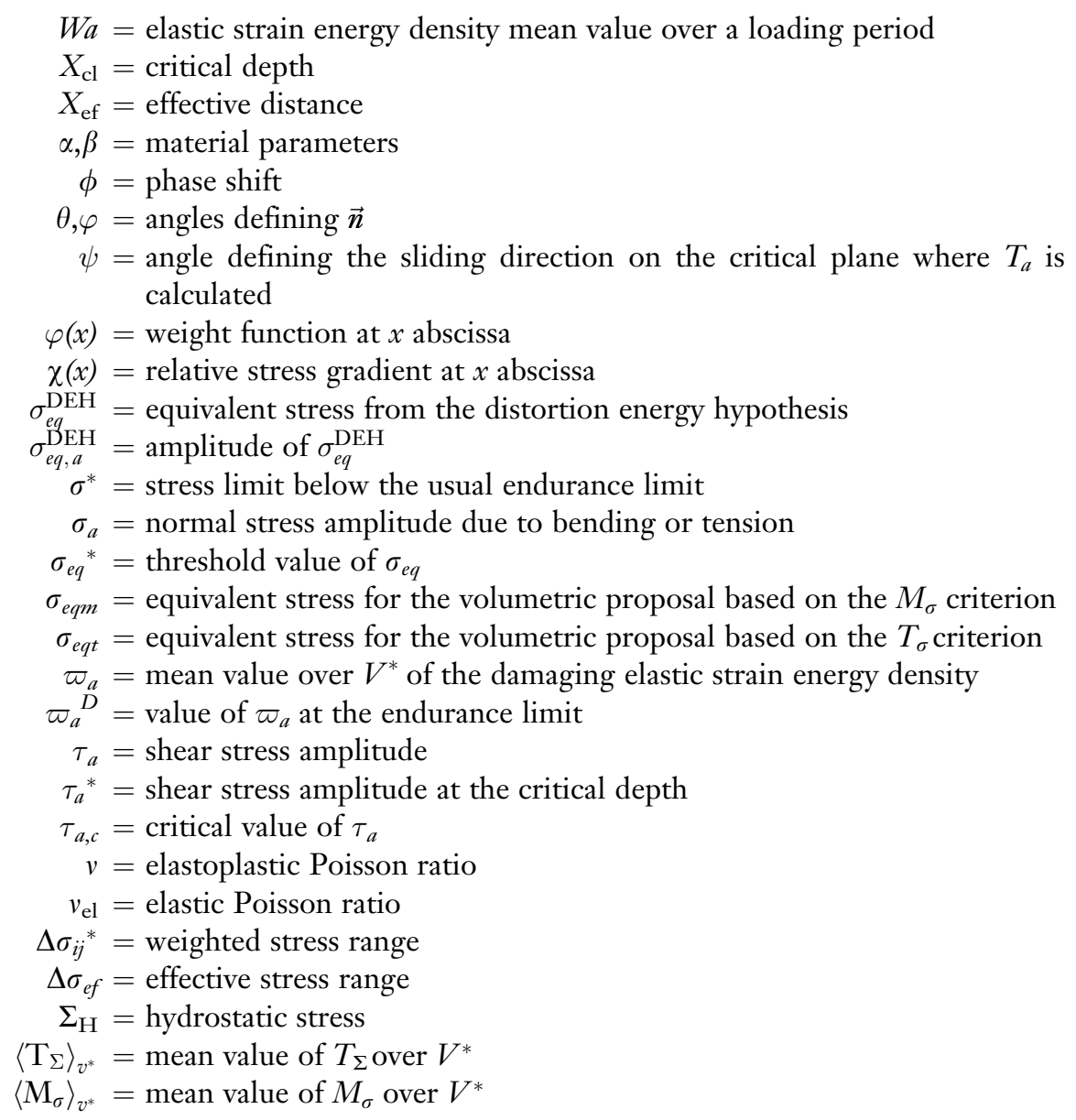

\section{INTRODUCTION}

Fatigue data from laboratory tests have to be used very carefully when designing real structures and for instance notched components. Using the theoretical stress concentration factor $K_{\mathrm{t}}{ }^{1}$, and the notch factor $K_{\mathrm{f}}$, to characterize the notch effect on the endurance limit is not always enough. These factors can be the same for two components with two different geometries even if their experimental fatigue limits are different. ${ }^{2}$ It is also well known in high cycle fatigue, that the load type has a significant influence on the fatigue strength: for example, the endurance limits in tension and in bending are different. $^{3}$ Generally, in fatigue design the transfer of fatigue data from specimens to components can be hindered by two major phenomena: the 'stress gradient effect' and the so called 'size effect'.

A good review of size and gradient effects is proposed by Papadopoulos ${ }^{4}$ showing that they are linked together; distinguishing them is not always easy. Fatigue data from Pogoretskii and Karpenko as reported in Ref. [5] prove that the specimen diameter influence on the fatigue limit is an order of magnitude higher than the effect of its length. In the same way, Phillips and Heywood's fatigue data under fully reversed tension ${ }^{6}$ show a very small pure size effect. On the contrary, data from Pavan ${ }^{7}$ and from Pogoretskii and Karpenko, as reported in Ref. [5], show a decrease of the fatigue limit with an increase of the specimen diameter and its length also. By analysing this data, Papadopoulos separates the pure size effect and the pure gradient effect. This author shows that the pure gradient effect, i.e. the volumetric stress distribution effect, is more important than the pure size effect. ${ }^{5}$ The machining process is also linked with this last effect because fatigue life also depends on the finishing state of the component surface (grinding, polishing, etc.). ${ }^{8}$

The aim of this paper is not to predict this 'technological size effect': the material, the surface state and surface layer of both specimen and component (with residual stresses, if any) are supposed identical. Furthermore, studying the pure stress gradient effect with experiments on notched specimens is not well adapted because in many cases, the presence of a notch involves high stress-strain concentrations and so local plastic strains. Pure stress gradient effect has to be separated from the local plasticity effect for which a cyclic-plastic material behaviour law 
must be considered to compute, by finite element analysis, the real stress-strain distributions.

After a review of some fatigue criteria from the literature which take into account the effect of the stress distribution on the fatigue limit, this paper presents a non-local evolution of the local fatigue criterion proposed by Papadopoulos. ${ }^{9}$ This evolution has been developed on the basis of the non-local energy based fatigue criterion proposed by Palin-Luc and Lasserre. ${ }^{10}$ Such calculation methods predict the fatigue limit corresponding to fatigue crack initiation. In experiments, the size of the nucleated fatigue crack is that which a fatigue testing machine can automatically detect: approximatively $0.5 \mathrm{~mm}$ (specimen stiffness decreasing); crack propagation is not considered hereafter. Comparison between experiments and the prediction of this proposal are also presented and compared to the predictions calculated with the local Papadopoulos criterion.

\section{SOME FATIGUE CRITERIA CONSIDERING THE STRESS DISTRIBUTION EFFECT}

A reliable design against fatigue requires a calculation method able to consider both the volumetric distribution of stresses and the loading type. Several methods are proposed in the literature to predict these effects: the critical layer of Flavenot and Skally, ${ }^{11}$ the effective distance of Pluvinage, ${ }^{2}$ the maximum stressed-strained volume of Sonsino, ${ }^{8}$ the volume influencing fatigue crack initiation proposed by Palin-Luc and Lasserre, ${ }^{10}$ and the Papadopoulos gradient dependent fatigue criterion. ${ }^{4}$ From a more general point of view many non-local failure criteria exist in many fields of research: Mroz and Sewerin, ${ }^{13}$ Kennedy and Nahan. ${ }^{14}$ This review is not exhaustive, only the first four methods are briefly presented in the following to show the evolution from a two dimensional proposal with a 'characteristic length' to three dimensional volumetric approaches with the concept of 'critical volume'.

\section{The critical layer}

Based on an idea proposed in 1954 by Stieler ${ }^{15}$ —but not verified at that time due to the lack of experimentsFlavenot and Skally proposed in 1983 a specific fatigue design criterion, called 'the critical layer'. ${ }^{11}$ Its aim was to model the gradient effect in multiaxial fatigue. Assuming that fatigue crack initiation is the consequence of shear stress acting on unfavourably orientated crystallographic planes in a polycrystalline material, these authors used, as a basis of their work, the Dang Van fatigue criterion. ${ }^{16}$ This criterion can be written as in Eq. (1); this means that no fatigue crack initiation is predicted to occur as long as the inequality is fulfilled. This is a linear combination of the shear stress amplitude $\tau_{a}(M, \vec{n}, t)$ acting at a point $M$ of the loaded component on the plane orientated by $\vec{n}$ and of the maximum hydrostatic stress $\Sigma_{\mathrm{H}, \max }(M)=\max _{t \in T}\left(\sigma_{\mathrm{kk}}(M, \mathrm{t}) / 3\right) ; a$ and $b$ are two material parameters.

$\max _{\vec{n}}\left\{\max _{t \in T}\left[\tau_{a}(M, \vec{n}, t)+a \Sigma_{H, \max }(M, t)\right]\right\} \leq b$

In a Dang Van diagram, Flavenot and Skally showed that for a given material all the experimental fatigue data are on a straight line for a specific depth just below the notch root (whatever the geometry of the notched specimen loaded in tension-compression). This depth was called the 'critical layer' $X_{\mathrm{cl}}$ and is supposed to be characteristic of the material microstructure. The order of magnitude of the depth of this layer is the same as the grain size. The thinner the microstructure is, the thinner 'the critical layer' is. To avoid fatigue crack initiation, the shear stress amplitude at the critical depth $\tau_{a}^{*}$ must be lower than the critical shear stress amplitude $\tau_{a, c}$ given by the Dang Van diagram for the corresponding maximum hydrostatic stress $\Sigma_{H, \max }{ }^{*}$.

\section{The effective distance}

A volumetric fatigue criterion, based on the stress field intensity model, was proposed by Pluvinage and his coworkers ${ }^{2,17}$ especially for notched shafts with a key slot. The authors assume that there is always a small plastic zone in fatigue failure whose size is of several grains. This is represented by the effective distance $X_{\text {ef }}$ just below the surface at the notch root. The role, in fatigue crack initiation, of the real elastoplastic stress distribution and the corresponding relative stress gradient at the notch root are taken into account by using this concept of effective distance. According to Pluvinage et al. $X_{\mathrm{ef}}$ represents the boundary of the stress relaxation; in other words, this distance shows the boundary point in the vicinity of the notch root where stresses cause plasticity.

The effective volume, where the fatigue damage process occurs, is limited at the notch root by a cylinder whose diameter is equal to the effective distance defined by the two following points:

- this is the distance between the notch root and the point where the relative stress gradient is very small, and

- this distance is supposed to be greater than the local plastic zone because the endurance limit is lower than the yield stress.

The relative stress gradient $\chi(x)$ at the notch root is defined by $\chi(x)=(1 / \sigma(x))(\mathrm{d} \sigma(x) / \mathrm{d} x)$ where $x$ is the 
distance from the notch root surface and $\sigma(x)$ is the stress at the point defined by $x$. A weighted stress range: $\Delta \sigma_{i j}{ }^{*}=\Delta \sigma_{y y} \varphi(x, \chi)$ is introduced to describe the influence of each stress tensor component on fatigue crack initiation. The weight function $\varphi(x, \chi)$ depends on both the component geometry and the load type. For instance, $\varphi(x, \chi)=1-x \chi$ for a round specimen, or a round shaft, with a key slot. ${ }^{18}$

The effective stress range is then defined by Eq. (2) as the mean value, over the effective distance, of the weighted stress $\Delta \sigma_{i j}{ }^{*}$.

$\Delta \sigma_{e f}=\frac{1}{X_{\text {ef }}} \int_{0}^{X_{\text {ef }}} \Delta \sigma_{y y} \varphi(x, \chi) \mathrm{d} x$

The fatigue criterion is defined by $\Delta \sigma_{e f} \leq \Delta \sigma_{e f}^{0}$, where $\Delta \sigma_{e f}^{0}$ is the value of the effective stress range for the endurance limit (long life) on smooth specimen: $\Delta \sigma_{e f}^{0}=2 \sigma_{s}$, where $\sigma_{s}$ is the fully reversed fatigue strength on smooth specimen.

\section{The highly stressed volume $V 90 \%$}

The concept of highly stressed volume was first developed by Kugel in $1961^{19}$ but could not be verified at that time because sufficient fatigue data was not available. The basic idea is that fatigue failure initiating at discontinuities is not restricted to the component surface but also includes a material region under the surface. Sonsino et al. ${ }^{8}$ define the maximum stressed-strained material volume $V 90 \%$ as the volume where the maximum local stress-strain is greater than $90 \%$ of the maximum stresses, and, respectively, for strains.

These authors determine the influence of the maximum strained material volume on the fatigue strength of steels from the fatigue data of Kloos. ${ }^{20}$ The local multiaxial stress-strain states is expressed by equivalent stresses and strains in order to quantify the relationship with the material volume $V 90 \%$. For ductile material and for stress-strain states with constant principal stress-strain directions, the distortion energy hypothesis (DEH) is used. $^{22}$ For strains in the elastic range, the equivalent stress is calculated according to Eq. (3) from the principal stresses $\sigma_{1}, \sigma_{2}$.

$\sigma_{e q}^{\mathrm{DEH}}=\sqrt{\sigma_{1}^{2}+\sigma_{2}^{2}-\sigma_{1} \sigma_{2}}$

If there are elastic-plastic strains, an equivalent strain is formed with Eq. (4) from the principal strains $\varepsilon_{1}, \varepsilon_{2}$.

$$
\varepsilon_{\mathrm{eq}}^{\mathrm{DEH}}=\frac{\varepsilon_{1}}{1-v^{2}} \sqrt{\left(1-v+v^{2}\right)\left(1+\left(\varepsilon_{1} / \varepsilon_{2}\right)^{2}\right)-\left(1-4 v+v^{2}\right)\left(\varepsilon_{1} / \varepsilon_{2}\right)}
$$

where $v=0.5-\left(0.5-v_{\mathrm{el}}\right) E_{\mathrm{s}} / E$ is the elastic-plastic Poisson ratio depending on the elastic Poisson ratio $v_{e l}$, $E_{\mathrm{s}}$ and $E$ are, respectively, the secant and the elastic Young moduli from the stress-strain curve. For notch factors lower than $K_{\mathrm{t}}=2.5, \sigma_{2}$ and $\varepsilon_{2}$ are determined as a function of the notch factor according to Neuber. ${ }^{23}$ Then the highly stressed-strained volume $V_{90 \%}$ is defined by the set of points where the equivalent stress is higher than $90 \%$ of the maximum equivalent stress.

From many fatigue experiments on steel (on $37 \mathrm{Cr} 4 \mathrm{~V}$ hardened and tempered steel for instance ${ }^{8}$ ) under alternating loading with different notches and load types, Sonsino and his co-workers proposed Eq. (5) if $V_{90 \%}$ is lower than $30 \mathrm{~mm}^{3} . \sigma_{e q, a, 0}^{\mathrm{DEH}}$ is the Von Mises equivalent stress amplitude according to the DEH in Eq. (3) corresponding to an experimental endurance limit (on a notched specimen) and $V_{90 \%, 0}$ is the corresponding highly stressed volume; $\sigma_{e q, a}^{\mathrm{DEH}}$ and $V_{90 \%}$ are the same parameters for the studied component.

$\sigma_{\mathrm{eq}, \mathrm{a}}^{\mathrm{DEH}} \leq \sigma_{\mathrm{eq}, \mathrm{a}, 0}^{\mathrm{DEH}}\left(\frac{V_{90 \%, 0}}{V_{90 \%}}\right)^{0.05}$

This threshold at a diameter of approximately $30 \mathrm{~mm}$ was also observed by Kloos; ${ }^{20}$ similar exponent values were also found for other heat-treatable steels, sintered steels and welded connections. ${ }^{21}$ For larger $V_{90 \%}$ volume, the acceptable equivalent stress amplitude is constant (Fig. 1).

This equation shows that for evaluating the fatigue strength of a component, a knowledge of only the local equivalent stress or strain in the fatigue critical area is not sufficient. The maximum stressed-strained material volume given by the local stress concentration and the load type must also be included.

\section{The volume influencing fatigue crack initiation $V^{*}$}

Palin-Luc and Lasserre ${ }^{10}$ proposed in 1998 an energy based multiaxial fatigue criterion for fully reversed sinusoidal loadings. This proposal uses the concept of volume influencing fatigue crack initiation around the critical point with regard to fatigue crack initiation. They consider, as a damaging parameter, the part of the mean value-over a loading period-of the volumetric elastic strain energy density $\mathrm{Wa}$ in Eq. (6), exceeding a threshold value $W a^{*}$. This threshold is material dependent and depends also on the triaxiality of stresses.

$W a(M)=\frac{1}{T} \int_{T} \sigma_{i j}(M, t) \varepsilon_{i j}^{e}(M, t) \mathrm{d} t$

From fully reversed fatigue experiments on a spheroidal graphite cast iron, these authors show that a stress limit 


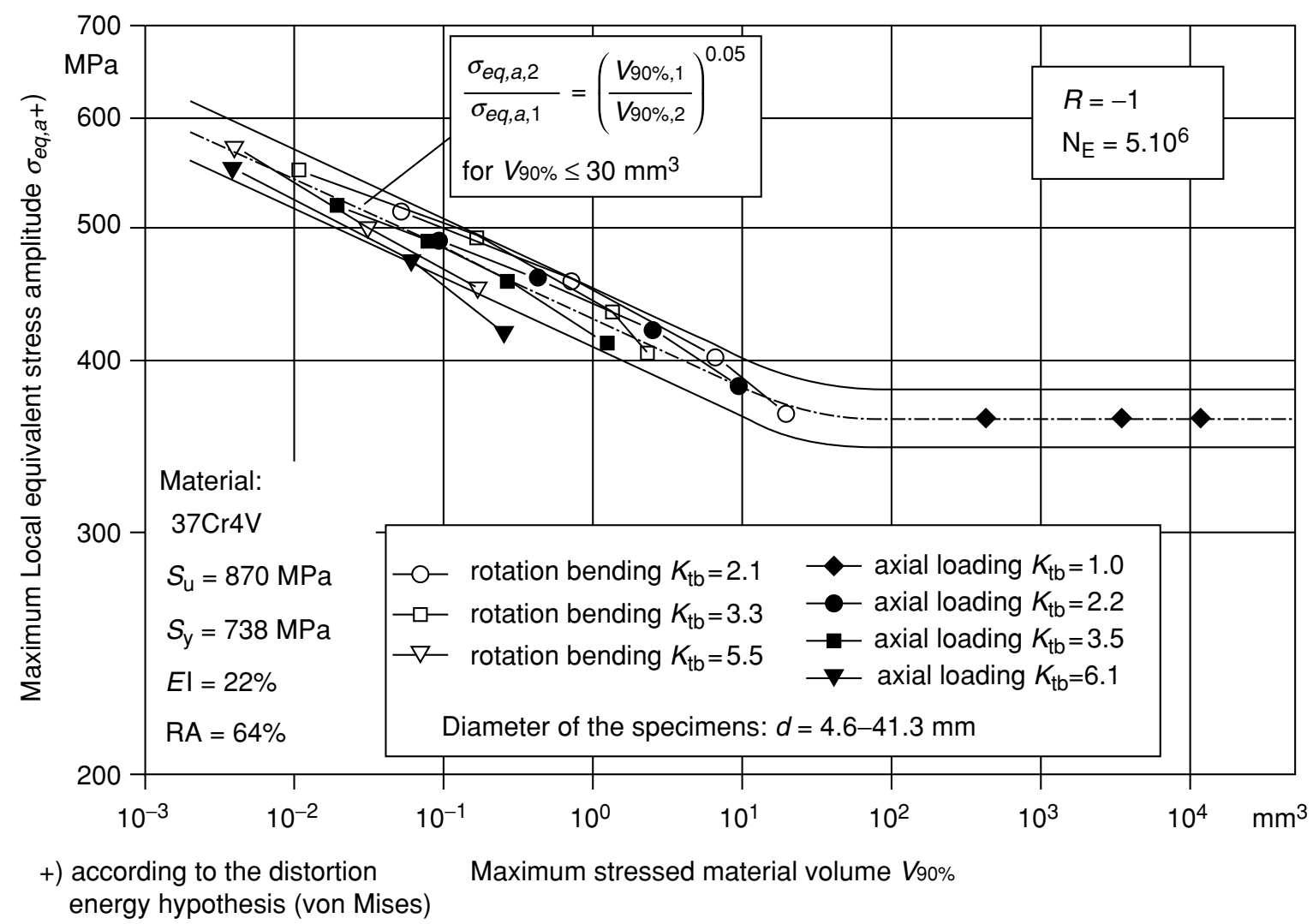

Fig. 1 Relation between the endurance limit as an equivalent stress amplitude vs. the maximum stressed volume $V_{90 \%}\left(\right.$ from Sonsino et $a l .^{8}$ ).

$\sigma^{*}$ can be defined below the conventional endurance limit $\sigma^{D}$. At a considered point, a stress amplitude lower than this stress limit does not initiate observable damage at a microscale (no microcrack). A stress amplitude between $\sigma^{*}$ and $\sigma^{D}$ only contributes to microdamage initiation which could develop if, either near this point or in the course of time there is a stress amplitude higher than $\sigma^{D}$. The stress limit $\sigma^{*}$ is considered as a limit of no damage initiation at the microscale. According to the authors, this stress limit can be estimated by Eq. (7) from the fully reversed endurance limits in tension $s_{-1}$ and in rotating bending $f_{R-1}$.

$\sigma^{*}=\sqrt{2\left(s_{-1}\right)^{2}-\left(f_{R-1}\right)^{2}}$

By reference to an homogenous uniaxial stress state (tension on smooth specimen) the energy threshold value corresponding to $\sigma^{*}$ is $W a^{*}=\left(\sigma^{*}\right)^{2} / 4 E$. Thus the volume influencing fatigue crack initiation is defined around each critical point (where $\mathrm{Wa}$ has a local maximum) by expression (8).

$V^{*}\left(C_{\mathrm{i}}\right)=\left\{M\right.$, such that $\left.W a(M) \geq W a^{*}\right\}$
Over this volume, the damaging parameter is the strain energy density $\varpi_{a}\left(C_{\mathrm{i}}\right)$ and is supposed to be constant for a given material at its endurance limit in a uniaxial stress state.

$\varpi_{a}\left(C_{\mathrm{i}}\right)=\frac{1}{V^{*}\left(C_{\mathrm{i}}\right)} \iiint_{V^{*}\left(C_{\mathrm{i}}\right)}\left[W a(x, y, z)-W a^{*}\left(C_{\mathrm{i}}\right)\right] \mathrm{d} v$

According to this criterion, the condition for no fatigue crack initiation is $\varpi_{a}\left(C_{\mathrm{i}}\right) \leq \varpi_{a}{ }^{D}$, where $\varpi_{a}{ }^{D}$ is the value of $\varpi_{a}$ at the endurance limit for a uniaxial stress state. ${ }^{\dagger}$ For multiaxial stress state at the fatigue critical point a multiaxial correction is proposed by these authors to take into account the effect of the triaxiality of stresses on the fatigue strength. Details are given in Ref. [10].

\section{Synthesis}

Of the four presented criteria, the Palin-Luc and Lasserre proposal is the only one able to distinguish both the effect on the endurance limit of the stress distribution

${ }^{\dagger}$ A uniaxial stress state is defined by a stress tensor with only one non zero principal stress. The stress state is multiaxial if there are two or three non zero principal stresses. 
and of the load type. But this is limited, at present, to fully reversed loadings. The critical layer and the effective distance proposals are easier to use but the fitting of the critical depth and the weight function is not very easy to achieve.

\section{A NON-LOCAL APPROACH}

\section{A multiaxial endurance criterion}

The non-local theory developed hereafter is based on the approach introduced by Papadopoulos in $1993^{9}$ and based on a mesoscopic analysis. Two endurance criteria were proposed: a critical plane criterion together with a 'global' one. Some studies ${ }^{24}$ proved the efficiency of these two criteria when compared with experimental data. Indeed, for metallic materials the proportional and non-proportional loading cases can be adequately reflected through this model. The two criteria of interest in this paper are built according to two root mean square values. The first one is related to the macroscopic resolved shear stress amplitude $T_{a}$ acting on all the possible directions (located by the angle $\psi$ ) of a material plane (defined by the spherical co-ordinates $\theta$ and $\varphi$ ): ${ }^{9,12,24}$

$$
\begin{aligned}
T_{\sigma}(\theta, \varphi) & =\sqrt{\frac{1}{\pi} \int_{\psi=0}^{2 \pi} T_{a}^{2}(\theta, \varphi, \psi) \mathrm{d} \psi} \quad \text { or } \\
M_{\sigma} & =\sqrt{\frac{5}{8} \frac{1}{\pi^{2}} \int_{\varphi=0}^{2 \pi} \int_{\theta=0}^{\pi} T_{\sigma}^{2}(\theta, \varphi) \sin \theta \mathrm{d} \theta \mathrm{d} \varphi}
\end{aligned}
$$

The second average measure is the hydrostatic stress $\Sigma_{H}$, i.e. the volumetric mean of the normal stresses acting on all the possible material planes:

$\Sigma_{H}=\frac{1}{4 \pi} \int_{\varphi=0}^{2 \pi} \int_{\theta=0}^{\pi} N(\varphi, \theta) \sin \theta \mathrm{d} \theta \mathrm{d} \varphi$

The two multiaxial endurance criteria in Eqs (12) and (13) are defined as an inequality applied to a linear combination of the average quantities proposed above. In the following, Eq. (12) will be called the 'critical plane' criterion because $\max _{\theta, \varphi}\left[T_{\sigma}(\theta, \varphi)\right]$ defines the material plane orientated by $\vec{n}(\theta, \varphi)$ where $T_{\sigma}$ is maximum; Eq. (13) will be called the 'global' criterion since $M_{\sigma}$ is the mean value of $T_{\sigma}$ over all the possible material planes at the considered point.

$$
\begin{aligned}
& \max _{\theta, \varphi}\left[T_{\sigma}(\theta, \varphi)\right]+a \Sigma_{H, \max } \leq b \\
& M_{\sigma}+\alpha \Sigma_{H, \text { max }} \leq \beta
\end{aligned}
$$

$a, b, \alpha$ and $\beta$ are four different material constants. They are, for instance, readily related to the fully reversed rotating bending fatigue limit, denoted as $f_{R-1}$, and to the fully reversed torsion fatigue limit, denoted by $t_{-1}$ :

$a=\frac{3 t_{-1}}{f_{R-1}}-\frac{3}{2}, \quad b=t_{-1}, \quad \alpha=\frac{3 t_{-1}}{f_{R-1}}-\sqrt{3}, \quad \beta=t_{-1}$

It is important to point out that at this stage of development the choice between a push-pull fatigue limit and a bending fatigue limit on smooth specimen - generating together a uniaxial stress state-for the identification of coefficients can not be justified.

\section{A non-local modelling of high cycle fatigue}

As explained in the introduction, a local approach is not enough to reflect all the experimental observations in high cycle fatigue (e.g. difference between tensioncompression and bending fatigue limits and notch effect). It seems then important to consider the stress distribution around a critical point. ${ }^{10}$

A first idea could be to evaluate an average over all the stressed elementary volume around a critical point and to build a criterion from mean values of relevant stress quantities. However, in a stressed volume all the points are not likely to take part in the fatigue damage mechanism or in other words do not represent potential crack nucleation sites. Indeed, it is known that cracks nucleate close to the surface of a loaded component. Moreover, when the local stress level is not high enough, some microstructural barriers, e.g. pearlite bands in a mild steel, can lead to a microcrack arrest. ${ }^{25}$ All these considerations lead to the introduction of a threshold value, denoted as $\sigma_{e q}{ }^{*}$, that represents a limit under which no local fatigue damage mechanism can act. ${ }^{26}$ This threshold stress is similar in mind to the $\sigma^{*}$ stress introduced by Palin-Luc and Lasserre. ${ }^{10}$

The two criteria described in the previous section gives a condition in Eq. (15) applied to the parameters $\max _{\theta, \varphi}\left[T_{\sigma}(\theta, \varphi)\right]$ or $M_{\sigma}$ which is enough to prevent the crack nucleation at critical points if a threshold value $\sigma_{e q t}{ }^{*}$ or $\sigma_{e q m}{ }^{*}$ is introduced:

$\max _{\theta, \varphi}\left[T_{\sigma}(\theta, \varphi)\right] \leq \sigma_{\text {eqt }}{ }^{*}-p_{t} \Sigma_{H, \max }$ or

$M_{\sigma} \leq \sigma_{e q m}{ }^{*}-p_{m} \Sigma_{H, \max }$

where $\sigma_{\text {eqt }}{ }^{*}$ and $p_{t}$ (respectively $\sigma_{\text {eqm }}{ }^{*}$ and $p_{m}$ ) are two new material constants that are different from the two coefficients $a$ and $b$ (respectively $\alpha$ and $\beta$ ) of the local approach. Let us define an equivalent stress for each local approach $\sigma_{e q t}$ and $\sigma_{e q m}$ given by Eqs (16) and (17): 
$\sigma_{e q t}=\max _{\theta, \varphi}\left[T_{\sigma}(\theta, \varphi)\right]+p_{t} \Sigma_{H, \max }$

$\sigma_{e q m}=M_{\sigma}+p_{m} \Sigma_{H, \max }$

These stress quantities are used to check, according to Eq. (15) how many points of the stressed volume are likely to suffer damage. In the following and to make the relations less cumbersome $\sigma_{e q}$ (if not specified) will represent both $\sigma_{e q t}$ and $\sigma_{e q m}$. Around a critical point $C_{\mathrm{i}}$ (where $\sigma_{e q}$ has a local maximum) all the points verifying $\sigma_{e q} \geq \sigma_{e q}{ }^{*}$ define a volume denoted as $V^{*}\left(C_{\mathrm{i}}\right)$ and called the crack initiation influencing volume as proposed in Ref. [10]:

$V^{*}\left(C_{\mathrm{i}}\right)=\left\{M\right.$ points around $C_{\mathrm{i}}$ so that, $\left.\sigma_{e q}(\mathrm{M}) \geq \sigma_{e q}{ }^{*}\right\}$

In a first approximation, it is proposed to carry out simple averages over $V^{*}$ of the two mechanical parameters used in the criterion in (see Eq. 19) and of the maximum hydrostatic stress in Eq. (20):

$$
\begin{aligned}
& \left\langle T_{\Sigma}\right\rangle_{V^{*}}=\frac{1}{V^{*}} \iiint_{V^{*}}\left(\max _{\theta, \varphi}\left[T_{\sigma}(\theta, \varphi)\right]\right) \mathrm{d} v \quad \text { or } \\
& \left\langle M_{\sigma}\right\rangle_{V^{*}}=\frac{1}{V^{*}} \iiint_{V^{*}} M_{\sigma} \mathrm{d} v \\
& \left\langle\Sigma_{H, \max }\right\rangle_{V^{*}}=\frac{1}{V^{*}} \iiint_{V^{*}}\left(\Sigma_{H, \max }\right) \mathrm{d} v
\end{aligned}
$$

In order to make the relations less cumbersome, $T_{\Sigma}$ will represent the maximum value of $T_{\sigma}$ over all the material planes.

Two new criteria can thus be defined as in Eqs (21) and (22)

$$
\begin{aligned}
& \left\langle T_{\Sigma}\right\rangle_{V^{*}}+p_{t}\left\langle\Sigma_{H, \max }\right\rangle_{V^{*}} \leq q_{t} \\
& \left\langle M_{\sigma}\right\rangle_{V^{*}}+p_{m}\left\langle\Sigma_{H, \max }\right\rangle_{V^{*}} \leq q_{m}
\end{aligned}
$$

Depending upon the chosen criterion, two new material parameters $q_{t}$ and $q_{m}$ are introduced. It must be pointed out that $\sigma_{e q t}{ }^{*}$ and $q_{t}$ (respectively $\sigma_{e q m}{ }^{*}$ and $q_{m}$ ) are different parameters, more exactly $q_{t}$ is higher than $\sigma_{e q t}{ }^{*}$ (respectively $q_{m}$ is higher than $\sigma_{e q m}{ }^{*}$ ). While $\sigma_{e q}{ }^{*}$ represents a fatigue threshold at some local points, $\mathrm{q}$ defines a limit for the 'averaged criterion' and encompasses all the potential nucleation sites into $V^{*}$. The crack initiation is then seen as the coalescence of many crack nuclei so as to form a crack of the same size order as the elementary material volume.

\section{Identification of the model parameters}

Each model requires the introduction of three parameters: $p_{t}, \sigma_{e q t}{ }^{*}$ and $q_{t}$ (respectively $p_{m}, \sigma_{e q m}{ }^{*}$ and $q_{m}$ ). Three fatigue reference tests are then necessary to estimate these coefficients. At least one of these tests must introduce a non-homogeneous stress distribution in the loaded samples. To reach simple analytical expressions, let us consider cylindrical test specimens with the same geometry and submitted to fully reversed tensioncompression, torsion and rotating bending. The three corresponding fatigue limits are denoted as $s_{-1}, t_{-1}$ and $f_{R-1}$. For these three load conditions, the relations in Eqs (21) and (22) lead to:

- Tension-compression test:

$$
\frac{s_{-1}}{2}+p_{t} \frac{s_{-1}}{3}=q_{t}
$$

or

$\frac{s_{-1}}{\sqrt{3}}+p_{m} \frac{s_{-1}}{3}=q_{m}$

$\sigma_{e q}{ }^{*}$ does not appear in Eqs (23) and (24) since all the points of the specimen are equally stressed.

- Torsion test:

$$
\begin{aligned}
& \frac{2}{3} t_{-1}\left(\frac{\sigma_{e q t}{ }^{*}}{t_{-1}}+\frac{1}{\frac{1+\sigma_{e q *^{*}}}{t_{-1}}}\right)=q_{t} \\
& \frac{2}{3} t_{-1}\left(\frac{\sigma_{e q m^{*}}}{t_{-1}}+\frac{1}{1+\frac{\sigma_{e q m^{*}}}{t_{-1}}}\right)=q_{m}
\end{aligned}
$$

$\sigma_{e q}{ }^{*}$ is now introduced since a shear stress gradient exists.

- Rotating bending test:

$$
\begin{aligned}
& \frac{2}{3}\left(\frac{f_{R-1}}{2}+p_{t} \frac{f_{R-1}}{3}\right)\left(\frac{\sigma_{e q t}{ }^{*}}{\frac{f_{R-1}}{2}+p_{t} \frac{f_{R-1}}{3}}+\frac{1}{\left.1+\frac{\sigma_{e q *^{*}}}{\frac{f_{R-1}+p_{t} f_{R-1}}{3}}\right)=q_{t}}\right. \\
& \frac{2}{3}\left(\frac{f_{R-1}}{\sqrt{3}}+p_{m} \frac{f_{R-1}}{3}\right)\left(\frac{\sigma_{e q m}{ }^{*}}{\frac{f_{R-1}}{\sqrt{3}}+p_{m} \frac{f_{R-1}}{3}}+\frac{1}{1+\frac{\sigma_{e q m m^{*}}}{\frac{f_{R-1}}{\sqrt{3}+p_{m}} \frac{f_{R-1}}{3}}}\right)=q_{m}
\end{aligned}
$$

$\sigma_{e q}{ }^{*}$ appears again because of the normal stress gradient.

After some calculations one can deduce the six coefficients of the two approaches:

$p_{t}=3 \frac{t_{-1}}{f_{R-1}}-\frac{3}{2}, p_{m}=3 \frac{t_{-1}}{f_{R-1}}-\sqrt{3}, q_{t}=q_{m}=\frac{t_{-1} s_{-1}}{f_{R-1}}$ 


$$
\begin{gathered}
\sigma_{\text {eqt }}{ }^{*}=\frac{t_{-1} s_{-1}}{f_{R-1}}\left[\frac{3}{4}+\frac{1}{2} \frac{f_{R-1}}{s_{-1}}\left(\sqrt{\left(\frac{3}{2} \frac{s_{-1}}{f_{R-1}}+1\right)^{2}-4}-1\right)\right] \\
\sigma_{\text {eqm }}{ }^{*}=\frac{t_{-1} s_{-1}}{f_{R-1}}\left[\frac{3}{4}+\frac{1}{2} \frac{f_{R-1}}{s_{-1}}\left(\sqrt{\left(\frac{3}{2} \frac{s_{-1}}{f_{R-1}}+1\right)^{2}-4}-1\right)\right]
\end{gathered}
$$

It is very important to notice from Eq. (29) that the two coefficients $q_{t}$ and $q_{m}$ are equal while the two coefficients $p_{t}$ and $p_{m}$ reflecting the sensitivity to the hydrostatic stress are different. The coefficients can be estimated if the following conditions are observed:

$\frac{f_{R-1}}{s_{-1}} \quad \frac{2}{3}$ and

$p_{t}>0 \Rightarrow \frac{t_{-1}}{f_{R-1}}>\frac{1}{2} \quad$ for the critical plane criterion

$\frac{f_{R-1}}{s_{-1}} \quad \frac{2}{3}$ and

$p_{m}>0 \Rightarrow \frac{t_{-1}}{f_{R-1}}>\frac{1}{\sqrt{3}} \quad$ for the global criterion

The comparison between the expressions of $a$ and $b$ coefficients (respectively $\alpha$ and $\beta$ ) of the local approaches in Eq. (14) and the coefficients $q_{t}$ and $p_{t}$ (respectively $q_{m}$ and $p_{m}$ ) of the non-local criterion in Eq. (29) shows that it is enough to know the ratio $\frac{s-1}{f_{R-1}}$ to shift from the local criterion to the non-local criterion. The ratio appears in the $\sigma_{\text {eqt }}{ }^{*}$ and $q_{t}$ expressions (respectively $\sigma_{\text {eqm }}{ }^{*}$ and $q_{\mathrm{m}}$ ) and reflects the volumetric stress distribution effect on fatigue strength.

\section{Stress heterogeneity factors}

As previously mentioned, a pure uniaxial tension stress state applied at some critical points of a structure is not enough to discriminate two loadings from the fatigue point of view. Nonetheless, the non-local approach here presented is able to distinguish between many distributions of the normal stress in a component. Let us take the example of some specimens submitted to five different loading cases: tension, four point rotating bending, four point plane bending, three point rotating bending, three point plane bending. For the sake of simplicity, cylindrical specimens will be used for rotating bending while plane bending will be applied to plane specimens (rectangular cross section). All these samples have the same length and same volume. For the tension loading, the stress distribution is uniform in the sample. The four point bending (plane and rotating) leads to a stress gradient which acts on a section but which remains constant along the specimen. For the three point bending (plane and rotating), there is a gradient which appears both along the specimen and in the specimen cross section. This last loading case leads to the more complex stress distribution in the sample.

The formulations of the two non-local approaches given by Eqs (21) and (22) can also be expressed by:

$\frac{1}{V^{*}} \iiint_{V^{*}} \frac{\sigma_{e q t}}{\sigma_{e q t}^{\max }} \mathrm{d} V \sigma_{e q t}^{\max } \leq q_{t}$

$\frac{1}{V^{*}} \iiint_{V^{*}} \frac{\sigma_{e q m}}{\sigma_{e q m}^{\max }} \mathrm{d} V \sigma_{e q m}^{\max } \leq q_{m}$

where $\sigma_{\text {eqt }}^{\max }$ and $\sigma_{\text {eqm }}^{\max }$ are the maximum values of the equivalent stresses acting on the cylindrical specimen. It now seems natural to introduce an heterogeneity factor denoted as $H_{t}$ (respectively $H_{m}$ ) which enables loading cases leading to the same maximum equivalent stress $\sigma_{\text {eqt }}^{\max }$ (respectively $\sigma_{\text {eqm }}^{\mathrm{max}}$ ) to be distinguished:

$H_{t}=\frac{1}{V^{*}} \iiint_{V^{*}} \frac{\sigma_{e q t}}{\sigma_{e q t}^{\max }} \mathrm{d} V$

$H_{m}=\frac{1}{V^{*}} \iiint_{V^{*}} \frac{\sigma_{e q m}}{\sigma_{e q m}^{\max }} \mathrm{d} V$

For the five loading cases discussed previously, $H_{t}$ and $H_{m}$ have the same expression $H$ depending on both the load type and the specimen cross section (the average carried out over the influence volume introduces no size effect):

Tension (round or square cross section):

$H=1$

Four point plane bending (square cross section):

$H=\frac{1}{2}\left[1+\frac{\sigma_{e q}{ }^{*}}{\sigma_{e q}^{\max }}\right]$

Four point rotating bending (round cross section):

$H=\frac{2}{3}\left[\frac{\sigma_{e q}{ }^{*}}{\sigma_{e q}^{\max }}+\frac{1}{1+\frac{\sigma_{e q}^{*}}{\sigma_{e q}{ }^{\max }}}\right]$

Three point plane bending (square cross section):

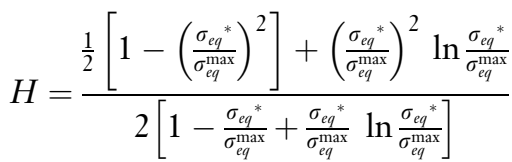


Three point rotating bending (round cross section):

$H=\frac{1}{3 \times\left(1-\frac{\sigma_{e q}{ }^{*}}{\sigma_{e q}^{\max }}\right)}\left[1+\frac{\sigma_{e q}{ }^{*}}{\sigma_{e q}^{\max }}-2\left(\frac{\sigma_{e q}{ }^{*}}{\sigma_{e q}^{\max }}\right)^{2}\right]$

The stress heterogeneity factors are functions of one material parameter $\sigma_{e q}{ }^{*}$ and of the maximum equivalent stress $\sigma_{e q}^{\max }$. They are sensitive to the load magnitude at a fixed cross section (shape and area). Since $H$ is the nondimensional mean value of the equivalent stress $\sigma_{e q}$ over the volume influencing fatigue crack initiation, it is also sensitive to the shape of the cross section or the shape of the specimen at a fixed maximum equivalent stress $\sigma_{e q}^{\max }$. Thus $H$ is stress distribution dependent. The evolution of $H_{t}$ vs. $\sigma_{e q}^{\max }$ for the five loading cases is shown in Fig. 2 for a high strength steel (30NCD16 quenched and tempered) described later in this paper. From this graph and according to Eqs (33) and (34), it seems obvious that the three point plane bending will lead to the highest fatigue limit and the tension fatigue limit will be the lowest. Moreover, the heterogeneity factors are very close to each other for the three-point plane or rotating bending. The fatigue limits should then be the same. The four point bending distinguishes more clearly plane and rotating bending. A greater difference in fatigue limits can then be expected for those loading cases, as shown in Ref. [27].

\section{Comparison of the non-local and local approaches}

In this section, the non-local model applied to the critical plane approach will be used. But all the conclusions will hold true for the 'global' approach.

The non-local approach as expressed in Eq. (21) keeps the same coefficient $p$ reflecting the hydrostatic stress sensitivity as the local approach (see Eqs (14) and (29)). An endurance line can then be plotted and its intersection with the ordinate axis depends on the three fatigue limits required for the identification. In the plane of this criterion, the same point will represent the fatigue limits of the five loading cases under discussion in the previous section: tension, four point rotating bending, four point plane bending, three point rotating bending, three point plane bending. The stress distribution effect is then taken into account by means of the averages over the influence volume while the multiaxiality effect is reflected through the chosen mechanical parameters $\max _{\theta, \varphi}\left[T_{\sigma}(\theta, \varphi)\right]$ and $\Sigma_{H, \max }$. Consequently, a combined tension and torsion loading (with or without phase shift) will be displayed by the same point as a combined bending and torsion loading. Figure 3(a) represents, for a high strength steel (30NCD16) described later in this paper, the endurance line and some points relative to combined plane bending and torsion loading with and without phase shift as well as combined rotating bending and torsion loading. All the points lie close to the material line corresponding to a perfect prediction. To compare those predictions with a local approach, the same fatigue data have been applied in the corresponding local approach (critical plane analysis) and are shown in Fig. 3(b).

It clearly appears that when using the local approach all the points are on the upper side (conservative side) of the endurance line. Moreover, the scatter is higher with the local criterion than with the non-local theory where all the points are very close to the threshold line. This first comparison proves the efficiency and the necessity of such a non-local approach.

\section{Gough and Pollard ellipse quadrant}

Let us study now the fatigue strength of a cylindrical specimen submitted to a fully reversed combined four point rotating bending and torsion loading. At any point of the specimen length and in a frame where the axes $x, y$ and $z$ are, respectively, directed along the radial, circumferential and axial directions, the bending torsion loading is defined by means of a dependence of the stress components with time (Eq. (42)).

$\Sigma_{z z}(t)=\sigma_{a} \sin (\omega t) \quad$ and $\quad \Sigma_{y z}(t)=\tau_{a} \sin (\omega t)$

where $\sigma_{a}$ and $\tau_{a}$ are the amplitudes of the normal and shear stresses. When dealing with in-phase bendingtorsion loading, the maximum value $T_{\Sigma}=\max _{\theta}\left[T_{\sigma}(\theta, \varphi)\right]$ and the parameter $M_{\sigma}$ are readily deduced: ${ }^{\theta, \varphi}$

$T_{\Sigma}=\sqrt{\frac{\sigma_{a}^{2}}{4}+\tau_{a}^{2}}$

$M_{\sigma}=\sqrt{\frac{\sigma_{a}^{2}}{3}+\tau_{a}^{2}}$

The equivalent stresses $\sigma_{e q t}$ and $\sigma_{e q m}$ calculated at the distance $r$ from the axial direction of the cylindrical specimen of radius $R$ is given by:

$\sigma_{\text {eqt }}=\frac{r}{R}\left(\sqrt{\frac{\sigma_{a}^{2}}{4}+\tau_{a}^{2}}+p \frac{\sigma_{a}}{3}\right)$

$\sigma_{e q m}=\frac{r}{R}\left(\sqrt{\frac{\sigma_{a}^{2}}{3}+\tau_{a}^{2}}+p \frac{\sigma_{a}}{3}\right)$

It is possible for the 'global' criterion $\left\langle M_{\sigma}\right\rangle_{\mathrm{V}^{*}}$ as expressed in Eq. (22) to reach an analytical expression close to the expression of an elliptical arc proposed by Gough and Pollard in 1951: ${ }^{28}$ 


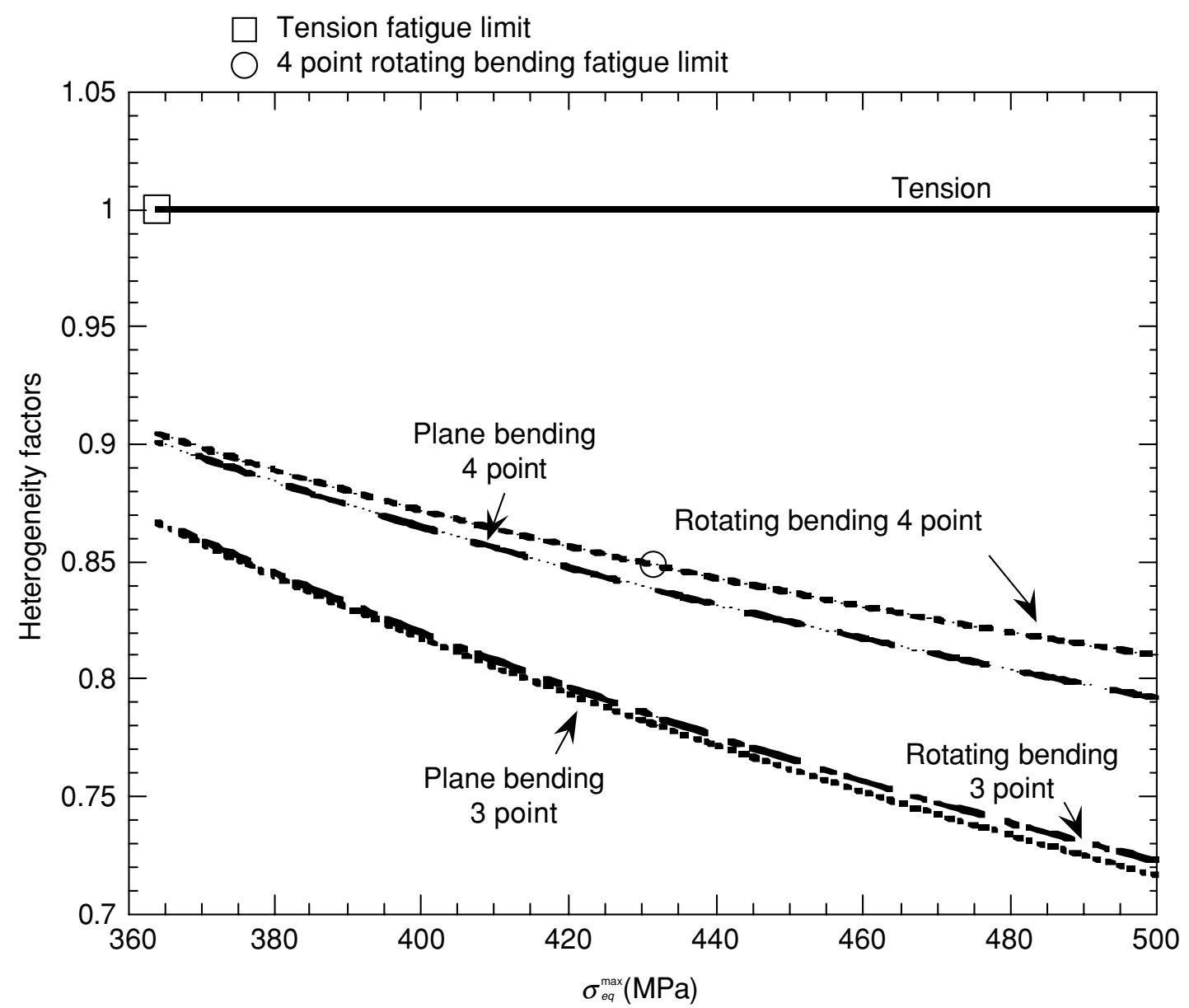

Fig. 2 Evolution of the heterogeneity factor with the amplitude of the equivalent stress at the critical point of a loaded component submitted to five loading cases: tension (cylindrical specimen), four point rotating bending (cylindrical specimen), four point plane bending (plane specimen), three point rotating bending (cylindrical specimen), three point plane bending (plane specimen). The material is the quenched and tempered high strength steel 30NCD16. ${ }^{10}$

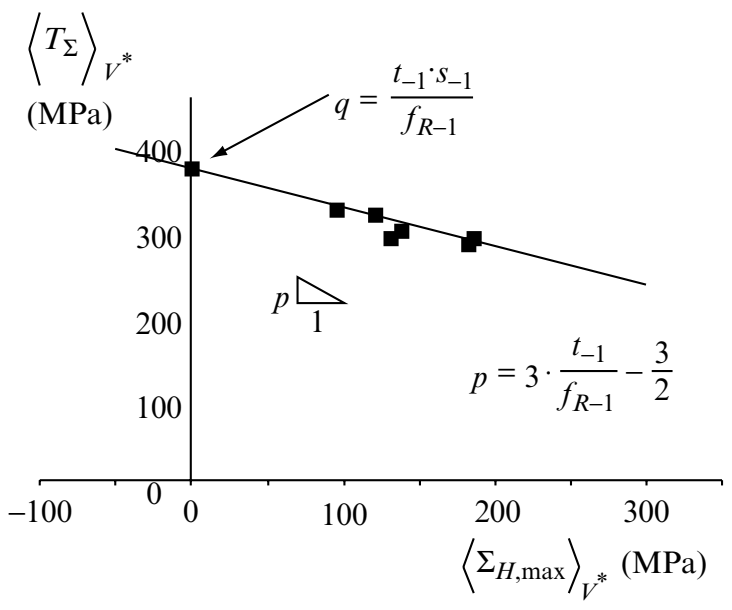

(a)

$$
\left\langle T_{\Sigma}\right\rangle_{V^{*}}+p_{t}\left\langle\Sigma_{H, \max }\right\rangle_{V^{*}} \leq q_{t}
$$

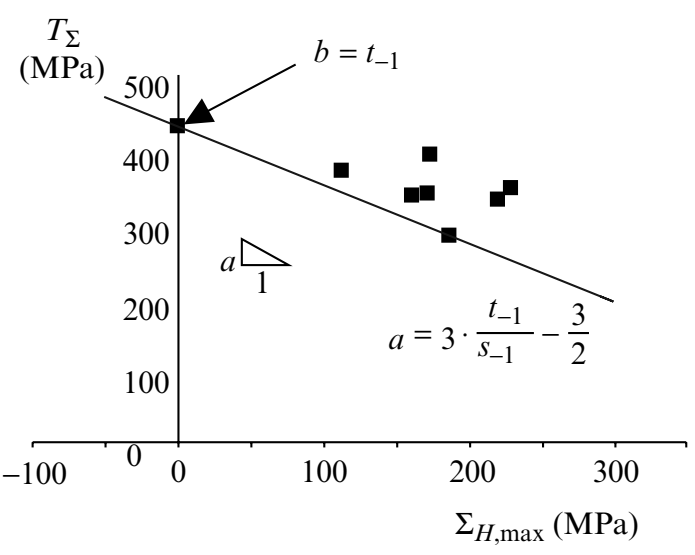

(b)

Fig. 3 (a) Non-local approach (Eq. (21)) and (b) local approach (Eq. (12)) of the critical plane criterion (Fatigue data on 30NCD16 ${ }^{10}$ ). 


$$
\frac{\tau_{a}^{2}}{\left(\frac{u \sigma_{e q}^{*}}{\sqrt{1-\frac{4}{q} p^{2}}}\right)^{2}}+\frac{\left(\sigma_{a}+\frac{p}{\frac{3}{4}\left(1-\frac{4 p^{2}}{9}\right)} u \sigma_{e q} *\right)^{2}}{\left(\frac{2 u \sigma_{e q}^{*}}{1-\frac{p^{2}}{9}}\right)^{2}}=1
$$

with

$$
u=\frac{\left(\frac{3}{2} \frac{q}{\sigma_{e q}{ }^{*}}-1\right)+\sqrt{\left(\frac{3}{2} \frac{q}{\sigma_{\varepsilon q}{ }^{*}}-1\right)^{2}+4\left(\frac{3}{2} \frac{q}{\sigma_{e q}{ }^{*}}-1\right)}}{2}
$$

For the critical plane criterion as expressed in Eq. (21), some numerical calculations are required to depict a curve also very close to the ellipse of Gough and Pollard. In Fig. 4, the two elliptical arcs are drawn for SAE 4340 steel studied by Findley. ${ }^{32}$ The fatigue limits for fully reversed tension-compression, torsion and rotating bending are, respectively:

$s_{-1}=400 \mathrm{MPa}, t_{-1}=285 \mathrm{MPa}$ and $f_{R-1}=460 \mathrm{MPa}$.

The corresponding 'global' criterion coefficients are: $q_{m}=248 \mathrm{MPa}, \sigma_{e q m}{ }^{*}=206 \mathrm{MPa}$ and $p_{\mathrm{m}}=0.359$ and $u=1.380$.

Let us recall that the ellipse found by Gough and Pollard has Eq. (49).

$\frac{\sigma_{a}^{2}}{f_{R-1}^{2}}+\frac{\tau_{a}^{2}}{t^{2}}=1$

\section{COMPARISON WITH EXPERIMENTAL DATA}

The extensive experimental studies carried out in the field of multiaxial high cycle fatigue in the LAMEFIP (Laboratoire Matériaux Endommagement Fiabilité et Ingénierie des Procédés) of Bordeaux ${ }^{10,29-31}$ are gathered together to check the accuracy of this model. Four different materials have been tested. Two quenched and tempered high strength steels: 30NCD16 (equivalent to BS 4S28-1964) and 35CD4 (equivalent to SAE 4135), an annealed mild steel XC18 (equivalent to SAE 1017) and a nodular cast iron (Afnor standard FGS 800-2). The mechanical properties of these materials are shown in Table 1. The identification of the model parameters $p_{t}$, $\sigma_{\text {eqt }}{ }^{*}$ and $q_{t}$ (respectively $p_{m}, \sigma_{e q m}{ }^{*}$ and $q_{m}$ ) can be done by means of three reference fatigue limits: tension, torsion and rotating bending with a stress ratio $R=-1$. For the 14 fatigue data presented in this paper, the fatigue limits have been deduced from a statistical analysis (staircase method) carried out on at least 15 smooth test specimens. Uniaxial and multiaxial fully reversed load conditions are analysed: plane bending, combined plane bending and torsion with or without phase shift, combined rotating bending and torsion. All these data are gathered in Table 2.

The prediction accuracy of the non-local approaches is checked according to the Relative Error of Prediction,

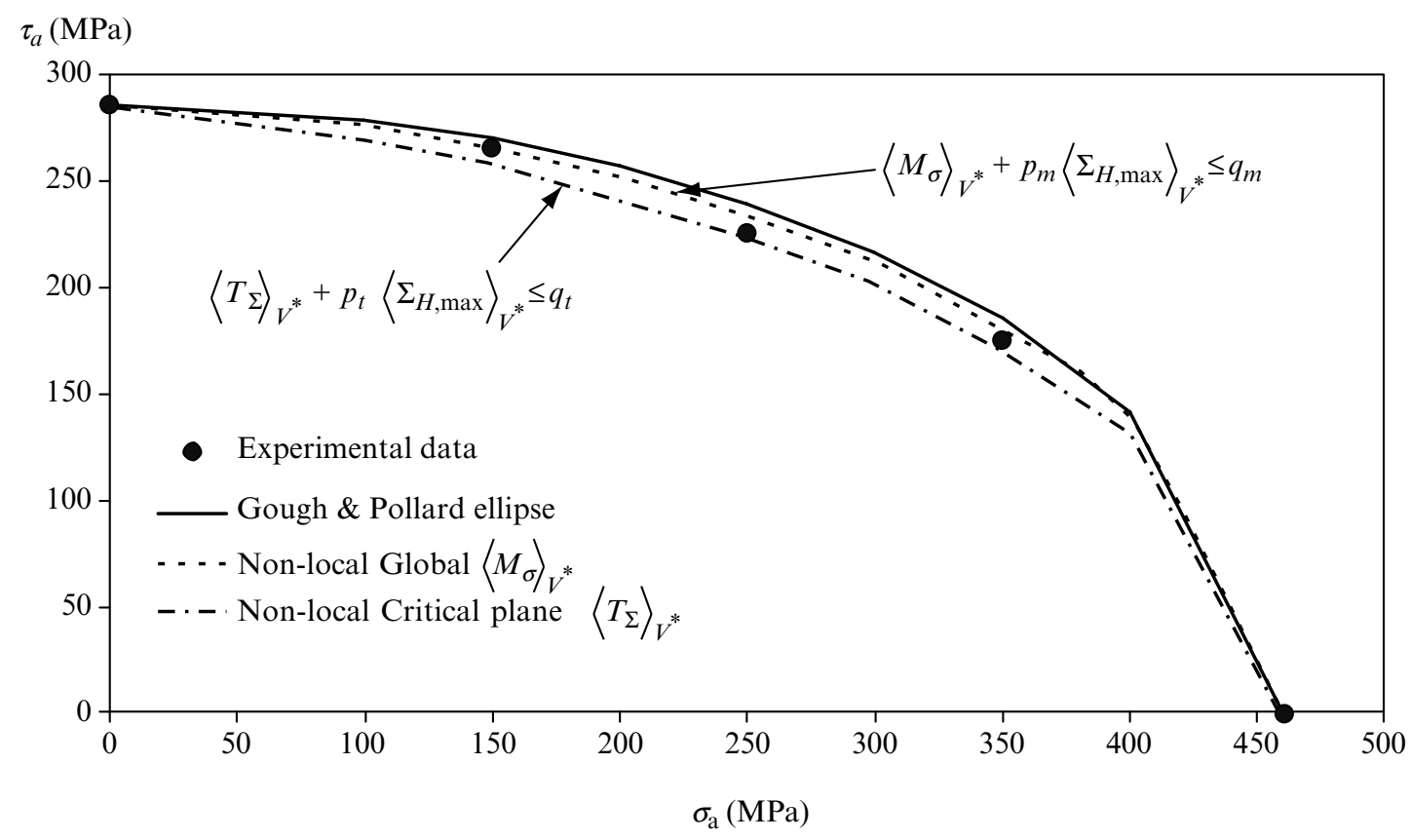

Fig. 4 Predictions of the non-local 'global' criterion (Eq. (22)) and non-local 'critical plane' criterion (Eq. (21)) for combined rotating bending and torsion loading. Data on the SAE 4340 steel from Findley. ${ }^{32}$ 
denoted as REP. Relative Error of Prediction represents the relative difference between the calculated fatigue limit $\sigma_{\text {calc }}{ }^{D}$ and the experimental one $\sigma_{\exp }{ }^{D}$. When a multiaxial loading is applied, the normal stress amplitude, i.e. $\sigma^{D}$, is used in the REP estimation in Eq. (50).

$\operatorname{REP}(\%)=\frac{\left(\sigma_{\text {calc }}^{D}-\sigma_{\text {exp }}^{D}\right)}{\sigma_{\text {exp }}^{D}} 100$

Table 1 Static mechanical properties of the tested materials from LAMEFIP $^{10,29-31}$ as reported in Ref. [10]

\begin{tabular}{lllrrlll}
\hline Material & $E(\mathrm{GPa}) v$ & $R e_{0.2}(\mathrm{MPa})$ & $R m(\mathrm{MPa})$ & $R u(\mathrm{MPa})$ & $A(\%)$ \\
\hline 30NCD16 & 200 & 0.3 & 1080 & 1200 & - & - \\
XC18 & 210 & 0.3 & 350 & 520 & 1530 & 24 \\
35CD4 & 200 & 0.3 & 1019 & 1123 & - & 13 \\
FGS 800-2 & 164.9 & 0.275 & 462 & 795 & 815 & 9 \\
\hline
\end{tabular}

Example: for the high strength steel 30NCD16, in combined rotating bending and torsion with the stress ratio $\sigma^{D} / \tau^{D}=1.03$, the prediction of the $\left\langle T_{\Sigma}\right\rangle_{V^{*}}$ criterion leads to $\sigma_{\text {calc }}{ }^{D}, \sigma_{\text {calc }}{ }^{D}=344 \mathrm{MPa}, \tau_{\text {calc }}^{D}=334 \mathrm{MPa}$ while experimental data are $\sigma_{\exp }{ }^{D}=337 \mathrm{MPa}, \tau_{\exp }{ }^{D}=$ $328 \mathrm{MPa}$. Thus the REP is:

$\operatorname{REP}(\%)=[(344-337) / 344] 100=2 \%$.

All the corresponding predictions are presented in Figs 5 and 6 for the non-local approaches $\left\langle T_{\Sigma}\right\rangle_{\mathrm{V}^{*}}$ (Eq. (21)) and $\left\langle M_{\Sigma}\right\rangle_{\mathrm{V}^{*}}$ (Eq. (22)).

It is clear in Figs 5 and 6 that the predictions are very good. All the errors are less than $10 \%$ and close to $5 \%$ except for one load condition which leads to an error of 14\% (high strength steel 30NCD16 loaded in combined plane bending torsion with a phase angle $90^{\circ}$ ). It should also be noticed that the two non-local approaches lead to the same prediction accuracy.

Table 2 Fatigue data on smooth specimens (from LAMEFIP ${ }^{10,29-31}$ as reported in Ref. [10]) and material parameters of the non-local approach (italic values were used to identify material parameters)

\begin{tabular}{|c|c|c|c|c|c|c|c|}
\hline Material and parameters & Loading & $\sigma^{D}(\mathrm{MPa})$ & $\tau^{D}(\mathrm{MPa})$ & $\sigma^{D} / \tau^{D}$ & $\phi(\mathrm{deg})$ & $\begin{array}{l}\text { Predicted } \sigma^{D}(\mathrm{MPa}) \\
\text { Critical plane } \\
\text { approach }\left\langle T_{\Sigma}\right\rangle_{\mathrm{V}^{*}}\end{array}$ & $\begin{array}{l}\text { Predicted } \sigma^{D}(\mathrm{MPa}) \\
\text { Global approach } \\
\left\langle M_{\sigma}\right\rangle_{\mathrm{V}^{*}}\end{array}$ \\
\hline 30NCD16 & Tension & 560 & - & - & - & & \\
\hline$\sigma_{\text {eqt }}{ }^{*}={\sigma_{\text {eqm }}}^{*}=292 \mathrm{MPa}$ & Rotating Bending & 658 & - & - & - & & \\
\hline$p_{t}=0.451, p_{m}=0.219$ & Torsion & - & 428 & - & - & & \\
\hline \multirow[t]{5}{*}{$q_{t}=q_{m}=364 \mathrm{MPa}$} & Plane Bending & 690 & - & - & - & 722 & 722 \\
\hline & Plane Bending + Torsion & 519 & 291 & 1.78 & 0 & 522 & 550 \\
\hline & Plane Bending + Torsion & 514 & 288 & 1.78 & 90 & 590 & 550 \\
\hline & Rotating Bending + Torsion & 337 & 328 & 1.03 & - & 344 & 356 \\
\hline & Rotating Bending + Torsion & 482 & 234 & 2.06 & - & 506 & 518 \\
\hline XC18 & Tension & 273 & - & - & - & & \\
\hline$\sigma_{\text {eqt }}{ }^{*}=\sigma_{\text {eqm }}{ }^{*}=139 \mathrm{MPa}$ & Rotating Bending & 310 & - & - & - & & \\
\hline$p_{t}=0.3, p_{m}=0.068$ & Torsion & - & 186 & - & - & & \\
\hline \multirow[t]{4}{*}{$q_{t}=q_{m}=164 \mathrm{MPa}$} & Plane Bending & 332 & - & - & - & 332 & 332 \\
\hline & Plane Bending + Torsion & 246 & 138 & 1.78 & 0 & 235 & 245 \\
\hline & Plane Bending + Torsion & 246 & 138 & 1.78 & 45 & 252 & 245 \\
\hline & Plane Bending + Torsion & 264 & 148 & 1.78 & 90 & 266 & 245 \\
\hline $35 \mathrm{CD} 4$ & Tension & 558 & - & - & - & & \\
\hline$\sigma_{\text {eqt }}{ }^{*}={\sigma_{\text {eqm }}}^{*}=353 \mathrm{MPa}$ & Rotating Bending & 581 & - & - & - & & \\
\hline$p_{t}=0.483, p_{m}=0.251$ & Torsion & - & 384 & - & - & & \\
\hline$q_{t}=q_{m}=369 \mathrm{MPa}$ & Plane Bending & 620 & - & - & - & 593 & 592 \\
\hline FGS 800-2 & Tension & 245 & - & - & - & & \\
\hline$\sigma_{\text {eqt }}{ }^{*}=\sigma_{\text {eqm }}{ }^{*}=162 \mathrm{MPa}$ & Rotating Bending & 280 & - & - & - & & \\
\hline$p_{t}=0.857, p_{m}=0.625$ & Torsion & - & 220 & - & - & & \\
\hline \multirow[t]{4}{*}{$q_{t}=q_{m}=193 \mathrm{MPa}$} & Plane Bending & 294 & - & - & - & 302 & 302 \\
\hline & Plane Bending + Torsion & 228 & 132 & 1.73 & 0 & 226 & 232 \\
\hline & Plane Bending + Torsion & 245 & 142 & 1.73 & 90 & 250 & 232 \\
\hline & Plane Bending + Torsion & 199 & 147 & 1.35 & 0 & 202 & 209 \\
\hline
\end{tabular}




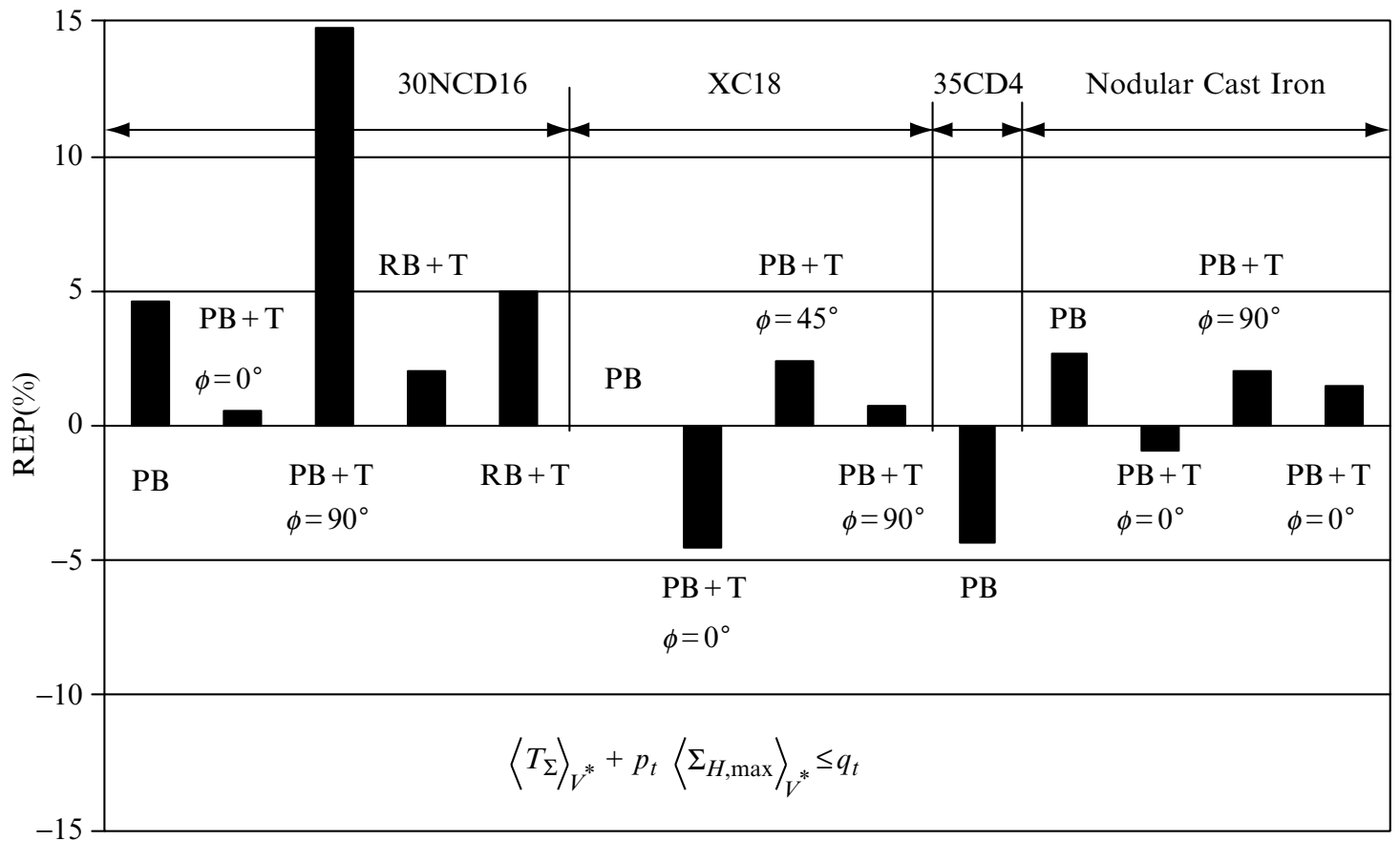

Fig. 5 Predictions of the non-local approach based on the 'critical plane' criterion (Eq. (21)) compared to experimental data from LAMEFIP ${ }^{10,29-31}$ as reported in Ref. [10].

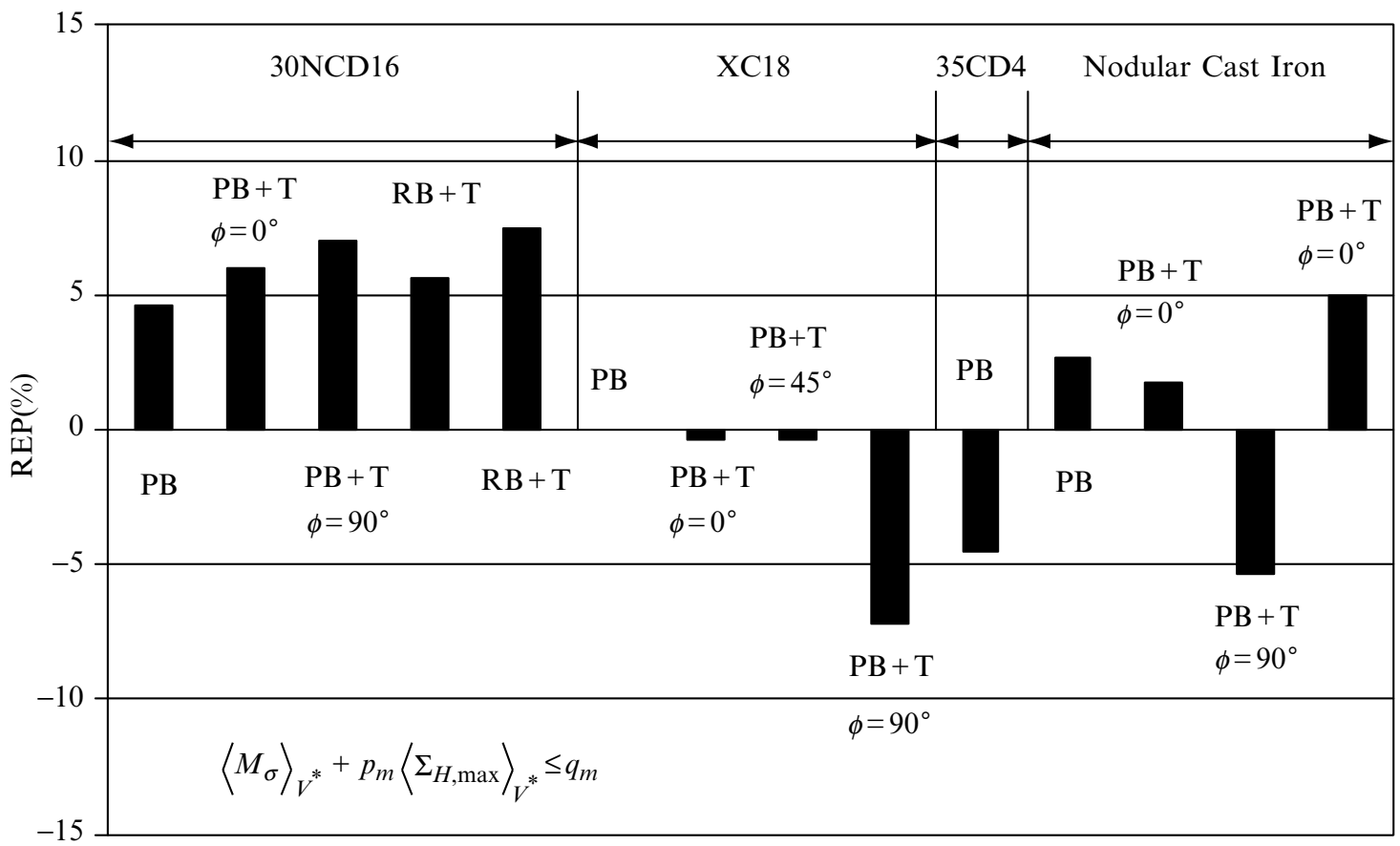

Fig. 6 Predictions of the non-local approach based on the 'global' criterion (Eq. (22)) compared to experimental data from LAMEFIP ${ }^{10,29-31}$ as reported in Ref. [10]. 


\section{DISCUSSION}

\section{Comparison with the local approaches}

To prove the need of such a non-local approach, it seems important to the authors to compare the above predictions with the predictions of the same approach applied in a local way, i.e. at the critical point. All the previous data are then used with the 'critical plane' criterion and the 'global' criterion presented as non-local approaches. The four coefficients $a, b, \alpha$ and $\beta$ are identified from the fully reversed fatigue limits in tension-compression and in torsion.

The Figs 7 and 8 show that unlike the non-local approach, the relative errors of prediction (REP) are much higher than 5\%. Indeed, almost all the REP values are greater than $10 \%$ and some of them are close to $25 \%$. Once more there is no evidence that any criterion is better than the other.

\section{Physical interpretation of the threshold $\sigma_{e q}{ }^{*}$}

According to Papadopoulos, ${ }^{9} T_{\sigma}$ and $M_{\sigma}$ are two ways to estimate the lower bound value of the mesoscopic plastic strain accumulated in a polycrystalline material loaded at its endurance limit. By considering the effect of the hydrostatic stress on fatigue mesocrack nucleation, Papadopoulos proposed two local endurance criteria in Eqs (12) and (13). The equivalent stress $\sigma_{e q}\left(\sigma_{e q t}\right.$ or $\sigma_{e q m}$, respectively for $T_{\sigma}$ and $M_{\sigma}$ ) can thus be seen as a 'measure' of the maximum cyclic stresses generating fatigue crack initiation. The corresponding limit value for the endurance limit is the stress above which fatigue microcracks nucleate in the material due to too much plastic mesostrain accumulation in unfavourably orientated grains. In practice, this limit value is identified from fatigue tests for which the smallest detected crack is macroscopic ( $0.5 \mathrm{~mm}$ to $1 \mathrm{~mm}$ length).

But, it is known that microcracks can exist in a specimen loaded at its endurance limit even if there is no macrocrack large enough to decrease the specimen stiffness (no fatigue crack detected by an automated fatigue testing machine). According to the Miller description ${ }^{25,33}$ crack initiation and propagation can be divided in three stages: (i) microstructural short crack, (ii) physically short crack, and (iii) long crack. This can be illustrated by Fig. 9. This author explains thus why nonpropagating fatigue microcracks exist at stress levels below the fatigue limit. ${ }^{33}$ The size of these nonpropagating microcracks is clearly dependent on the material microstructure and more precisely, dependent on microstructural barriers: grain boundaries, pearlite bands, etc... Those barriers are responsible for crack arrest.

According to Plumtree, ${ }^{34}$ a threshold stress range can also be defined below the conventional endurance limit.
This stress level is just sufficient to initiate and grow a short fatigue crack; its value increases with the crack depth and reaches a maximum corresponding to the endurance limit. For instance, the Plumtree intrinsic threshold range is $214 \mathrm{MPa}$ for a $3-\mu \mathrm{m}$ crack on smooth 2024-T351 aluminium alloy specimens loaded in fully reversed tension, and the corresponding endurance range is $246 \mathrm{MPa}$. Palin-Luc et al. ${ }^{10,26,35}$ proposed also a stress limit below the conventional endurance one. This threshold was observed on smooth specimens in a spheroidal graphite cast iron loaded in fully reversed plane bending.

For a polycrystalline metal, the proposed threshold equivalent stress $\sigma_{e q}{ }^{*}$ is similar in mind with the previous threshold. Below the conventional endurance limit (e.g. asymptotic stress of the $\mathrm{S}-\mathrm{N}$ curve), this threshold of the cyclic stress state (uniaxial or multiaxial) is the lowest value of $\sigma_{e q}$ above which microcracks can propagate through microstructural barriers up to a detectable fatigue macrocrack.

For a fully reversed uniaxial stress state, Table 3 gives both the values of the threshold stress amplitude $\sigma^{*}$ corresponding to $\sigma_{e q}{ }^{*}$ and the stress limit proposed by Palin-Luc and Lasserre. ${ }^{10}$ For the four tested materials, this table shows that the proposed threshold equivalent stress leads to very similar values to those proposed in Ref. [10] from a non-local energy based fatigue criterion. In the material, the set of points where the equivalent stress is higher than the proposed threshold equivalent stress can participate in fatigue crack nucleation because the stress level is high enough to allow microcracks and microdefects to grow up to a macrocrack. Considering this threshold together with a non-local fatigue criterion permits one to take into account in a fatigue criterion, by an indirect way, the effect of the microstructure on the fatigue limit.

\section{CONCLUSION AND PROSPECTS}

The non-local fatigue criteria presented from the local 'critical plane' and 'global' proposals of Papadopoulos are in very good agreement with experiments on smooth specimens in high cycle multiaxial fatigue. The main advantage of this volumetric approach is to predict the fatigue strength of metal whatever the load type: it distinguishes tension from bending (plane or rotating) and under combined loading its predictions are close to the Gough and Pollard ellipse quadrant for combined bending and torsion. This property is similar to that of the energy based fatigue criterion of Palin-Luc and Lasserre, ${ }^{10}$ who proposed also experiments to prove that a stress limit, denoted $\sigma^{*}$, exists below the conventional endurance one. ${ }^{26,35}$ Around a critical point in fatigue, all the points of the metal loaded with a stress amplitude 


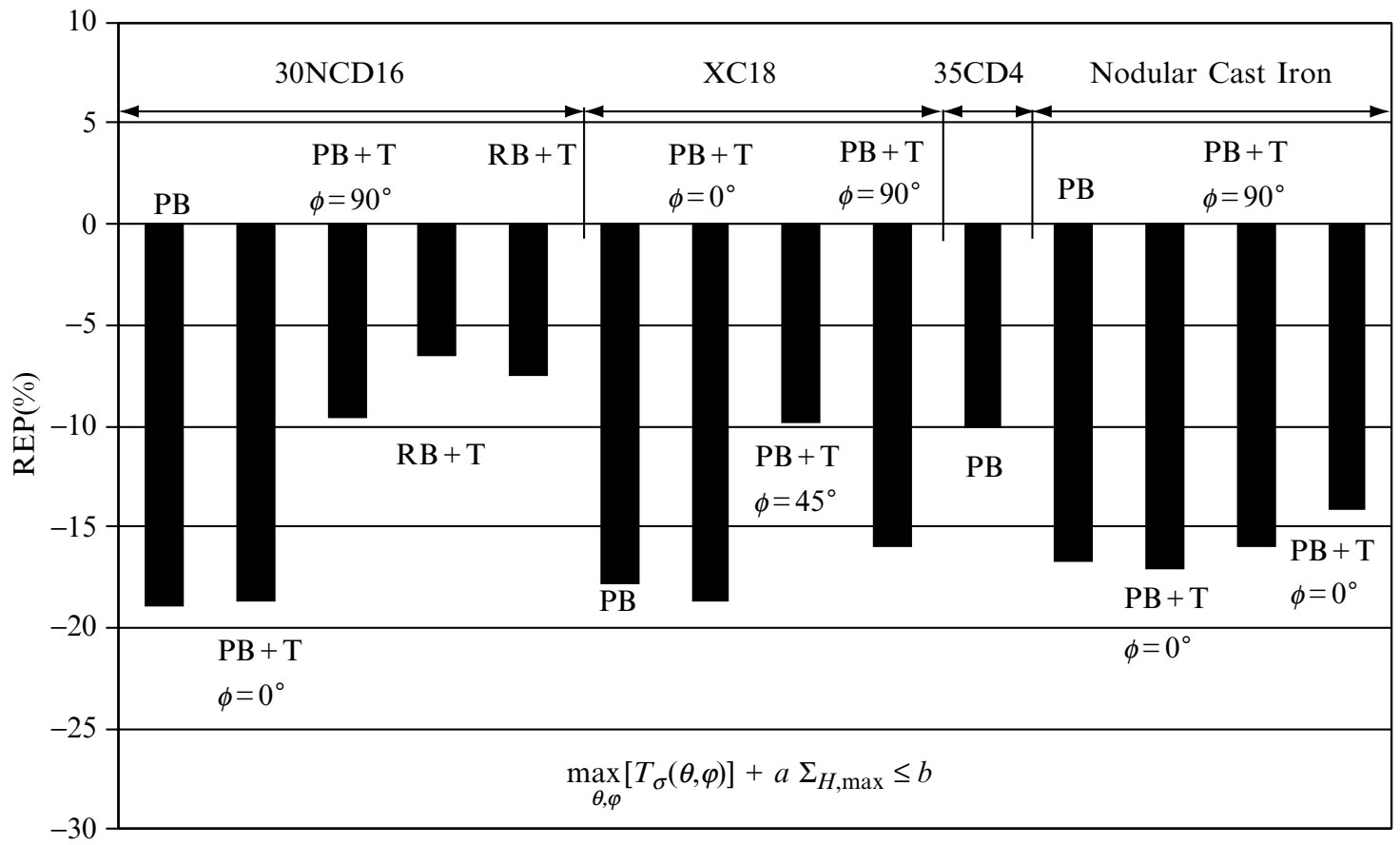

Fig. 7 Predictions of the local 'critical plane' criterion (Eq. (12)) compared to experimental data from LAMEFIP ${ }^{10,29-31}$ as reported in Ref. [10].

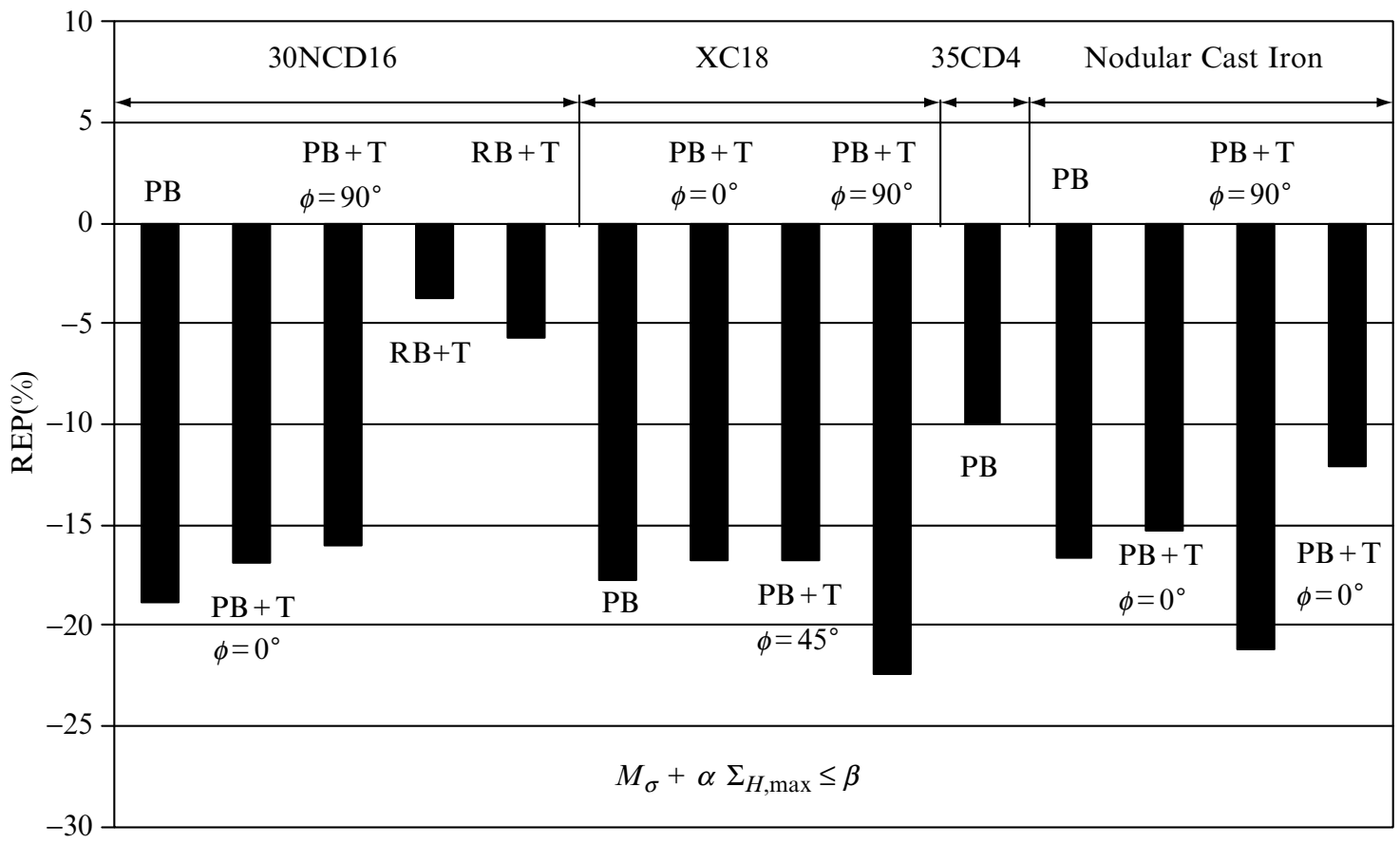

Fig. 8 Predictions of the local 'global' criterion (Eq. (13)) compared to experimental data from LAMEFIP ${ }^{10,29-31}$ as reported in Ref. [10]. 


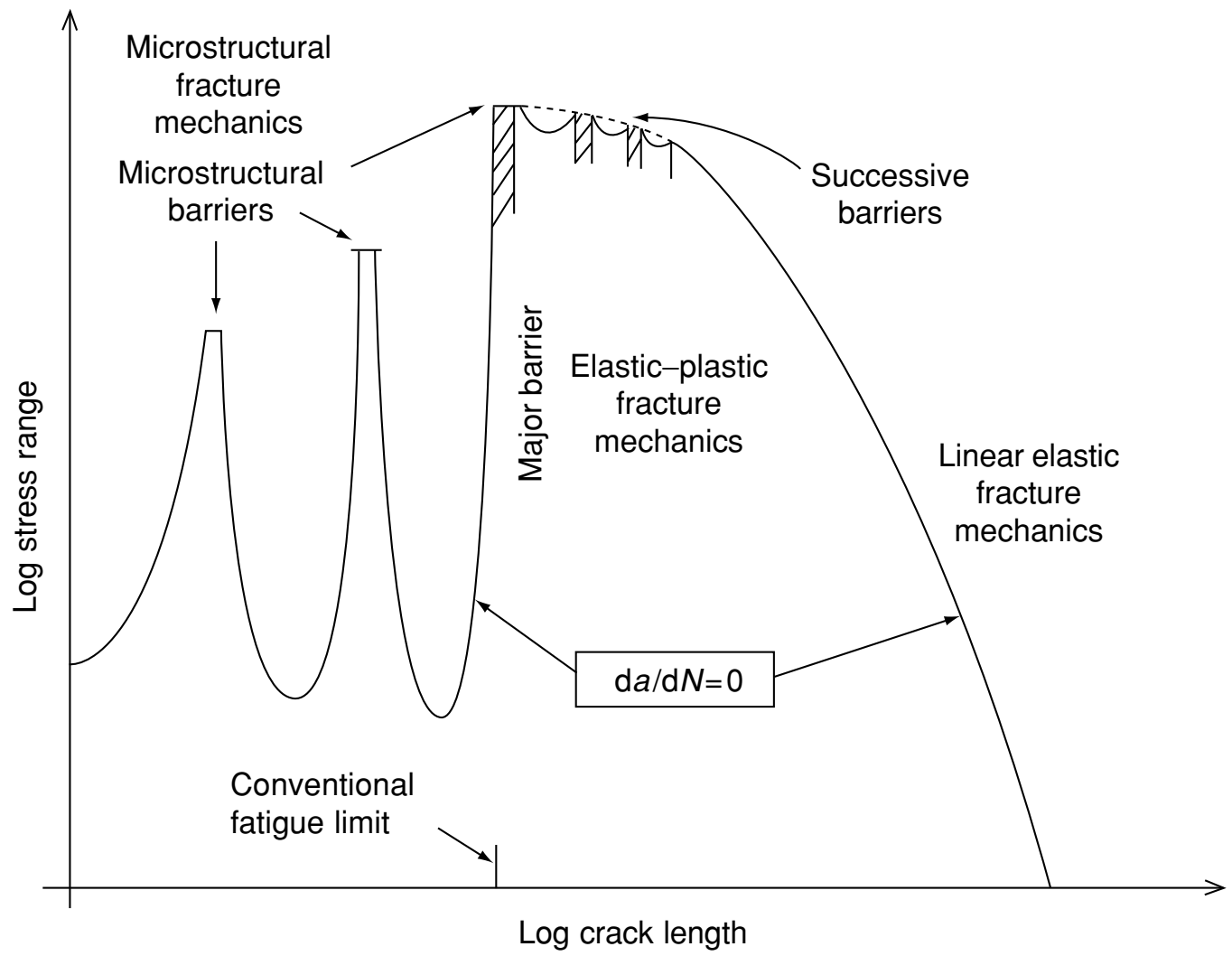

Fig. 9 Fatigue limit evolution of polycrystalline metal expressed as non propagating crack contour from Ref. [25].

Table 3 For fully reversed uniaxial stress state, comparison between the threshold stress limits from the present proposal and from the work of Palin-Luc and Lasserre. ${ }^{10}$

\begin{tabular}{lll}
\hline Material & $\sigma^{*}(\mathrm{MPa})$ proposed & $\sigma^{*}(\mathrm{MPa})$ from Palin-Luc ${ }^{10}$ \\
\hline 30NCD16 & 447 & 441 \\
XC18 & 233 & 230 \\
35CD4 & 535 & 534 \\
FGS 800-2 & 210 & 204 \\
\hline
\end{tabular}

higher than this threshold participate in damage nucleation. A physical significance of the volume influencing fatigue crack initiation is thus proposed. Since each load type is distinguished the ability of the proposal to calculate $\mathrm{S}-\mathrm{N}$ curves from a single reference $\mathrm{S}-\mathrm{N}$ curve should be investigated for lives between $10^{5}$ cycles and long life. Considering the volumetric distribution of stresses should allow good predictions of the fatigue limit of notched specimens and real components. This has to be verified in the near future, but in this case elastoplastic finite element analysis will be necessary to compute the real stress-strain distribution around the notch. At the moment the non-local approach presented in this paper is not able to predict the particular role played by the surface layer of a component (roughness, residual stresses, inclusions, defects etc.). In the future, a probabilistic approach could be imagined to consider the distribution of defects in the volume influencing fatigue crack initiation. This could be done by reference to the work of Hild and Roux for instance. ${ }^{36}$

Even if further research has to be carried out to propose to design departments, a reliable fatigue criterion capable of predicting a failure probability on a real component including notches, defects, residual stresses, and a specific roughness, the non-local approach seems worth proposing to industry as a deterministic criterion without the difficult choice of the proper uniaxial reference endurance limit that reflects best the stress distribution in the component (tension, plane bending, rotating bending), and a criterion which predicts the effect of notch and stress gradient on the fatigue limit.

\section{REFERENCES}

1 Peterson, R. (1972) Stress Concentration Factors. WileyInterscience publication.

2 Qylafku, G., Azari, Z., Kadi, N., Gjonaj, M. and Pluvinage, G. (1999) Application of a new model proposal for the fatigue life prediction on notches and key-seats. Int. F. Fatigue 21, 753-760. 
3 Bathias, C. and Bailon, J.-P. (1997) La Fatigue Des Matériaux et Des structures, Hermès, Paris.

4 Papadopoulos, I. V. and Panoskaltsis, V. P. (1996) Invariant Formulation of a gradient dependent multiaxial high-cycle fatigue criterion. Engng Fract. Mechanics 55, 513-528.

5 Papadopoulos, I. V. and Panoskaltsis, V. P. (1994) Gradient dependent multiaxial high-cycle fatigue criterion. In: Proceedings of the 4th International Conference on Biaxial/Multiaxial Fatigue, Vol. 1, pp. 461-476. SF2M Ed., France.

6 Phillips, C. E. and Heywood, R. B. (1951) The size effect in fatigue of plain and notched steel specimens loaded under reversed direct stress. In: Proceedings I. Mech. E. 165, 113.

7 Pavan, A. (1979) Contribution aux calculs d'organes d'ensembles mécaniques par rapport à la limite de fatigue. Explication des principaux facteurs, $\mathrm{PhD}$ Thesis, University Reims, France.

8 Sonsino, C. M., Kaufmann, H. and Grubisic, V. (1997) Transferability of material data for the example of a randomly loaded forged truck stub axle. SAE Technical Paper Series No. 970708, 1-22.

9 Papadopoulos, I. V. (1993) Fatigue limit of metals under multiaxial stress conditions: the mesoscopic approach. Technical Note No. I.93.101. Commission of the European Communities, Joint. Research Centre, ISEI/IE 2495/93.

10 Palin-Luc, T. and Lasserre, S. (1998) An energy based criterion for high cycle multiaxial fatigue. Eur. F. Mechanics, A/Solids 17, 237-251.

11 Flavenot, J.-F. and Skalli, N. (1993) L'épaisseur de couche critique ou une nouvelle approche du calcul en fatigue des structures soumises à des sollicitations multiaxiales. Rev. Mécanique Matériaux Electricité 397, 15-25.

12 Morel, F. (2000) A critical plane approach for life prediction of high cycle fatigue under multiaxial variable amplitude loading. Int. 7. Fatigue 22, 101-119.

13 Seweryn, A. and Mroz, Z. (1998) On the criterion of damage evolution for variable multiaxial stress states. Int. F. Solids Structures 35, 1589-1616.

14 Kennedy, T. C. and Nahan, M. F. (1997) A simple nonlocal damage model for predicting failure in a composite shell containing a crack. Composite Structures 39, 85-91.

15 Stieler, M. (1954) Untersuchungen über die dauerschwingsfestikeit metallisher bauteile bei raumtemperatur. Ph'D Thesis, Technische Kochschule-Stuttgart.

16 Dang Van, K. (1993) Macro-micro approach in high-cycle multiaxial fatigue. In: Advances in Multiaxial Fatigue, ASTM STP 1191 (Edited by D. L. McDowell and R. Ellis). ASTM, Philadelphia, USA, pp.120-130.

17 Pluvinage, G. (1997) Notch effect in high cycle fatigue. In: Proc. Icf9 3, 1239-1250.

18 Kadi, N., Azari, Z., Qylafku, G., Gilbert, G. and Pluvinage, G. (1999) La modélisation en fatigue des arbres clavetés. In: Proceedings of the Instruc 4, SF2M, Paris, pp. 121-128.

19 Kugel, R. (1961) A relation between theoretical stress concentration factor and fatigue notch factor deduced from the concept of highly stressed volume. In: ASTM Proc. 61, $732-748$.
20 Kloos, K. H. (1981) Grösseneinfluss und dauerfestikeitsengenschaften under besondered berücksichtigung optimierter oberflächenbehaundlung. Werktofftechnick 12, 134-142.

21 Sonsino, C. M. (1993) Zur bewertung des Schwingfestikeitsverhaltens von bauteilen mit hilfe örtlicher beanspruchungen. Konstruktion 45, 25-33.

22 Grubisic, V. and Sonsino, C. M. (1982) Influence of local strain distribution on the low-cycle fatigue behaviour of thin-walled structures. In: ASTM STP 770, pp. 612-629.

23 Neuber, H. (1985) Kerbspannungslehre theorie der spannungskonzentration genaue berechnung der festigkeit. Springer Verlag, Heilderberg, Berlin.

24 Morel, F. (2001) A critical plane fatigue model applied to out-of-phase bending and torsion load conditions. Fatigue Fract. Engng Mater. Struct. 24, 153-164.

25 Miller, K. J. (1993) Materials science perspective of metal fatigue resistance. Mat. Sci. Technol. 9, 453-462.

26 Palin-Luc, T., Lasserre, S. and Bérard, J.-Y. (1998) Experimental investigation on the significance of the conventional endurance limit of a spheroidal graphite cast iron. Fatigue Fract. Engng Mater. Struct. 21, 191-200.

27 Barrault, J. and Lasserre, S. (1980) Limites de fatigue de l'acier $35 \mathrm{CD} 4$ en flexion rotative et en flexion plane. Rev. Mécanique Matériaux Electricité 369, 275-278.

28 Gough, H. J., Pollard, H. V. and Clenshaw, W. J. (1951) Some experiments on the resistance of metals to fatigue under combined stresses. Aeronautical research council reports and memoranda. London.

29 Froustey, C. (1987) Fatigue multiaxiale en endurance de l'acier 30NCD16. PhD Thesis, E.N.S.A.M. CER de Bordeaux, France.

30 Dubar, L. (1992) Fatigue multiaxiale des aciers. Passage de l'endurance à l'endurance limitée. Prise en compte des accidents géométriques. PhD Thesis, E.N.S.A.M. CER de Bordeaux, France.

31 Galtier, A. (1993) Contribution à l'étude de l'endommagement des aciers sous sollicitations uni ou multiaxiales, $\mathrm{PhD}$ Thesis, E.N.S.A.M. CER de Bordeaux, France.

32 Findley, W. (1956) Theory for combined bending and torsion fatigue with data for SAE 4340 steel. In: Proceedings of the International Conference on Fatigue of Metal, I. Mech. E. London, England, pp. 150-157.

33 Miller, K.-J. (1997) The three thresholds for fatigue crack propagation. In: Fatigue and Fracture Mechanics, 27, ASTM STP 1296, (Edited by R. S. Piascik, J. C. Newman and N. E. Dowling), pp. 267-286.

34 Plumtree, A. (1999) Threshold stress range for short crack growth. In: Engineering Against Fatigue (Edited by J. H. Beynon, M. W. Brwon, T. C. Lindley, R. A. Smith, and B. Tomkins), A. A. Balkema, Rotterdam, pp. 55-61.

35 Palin-Luc, T., Lasserre, S. and Bérard, J.-Y. (1999) Une limite de non propagation des microfissures inférieure à la limite d'endurance conventionnelle sur une fonte GS, 14ème Congrés Français de Mécanique, AUM, 30 Août - 3 September, Toulouse, France.

36 Hild, F. and Roux, S. (1991) Fatigue initiation in heterogeneous brittle materials. Mechanics Res. Comms. 18, 409-414. 
